$\underline{\text { José Antonio Moreno Molina }^{1}}$

\title{
El ámbito objetivo de aplicación de la ley de contratos del sector público
}

SUMARIO: I. EL NUEVO ENFOQUE DE LA LEGISLACIÓN DE CONTRATOS. II. LA TIPOLOGÍA DE ENTIDADES Y CONTRATOS EN LA LEY DE CONTRATOS DEL SECTOR PÚBLICO. LA NUEVA CATEGORIZACIÓN DE LOS CONTRATOS ADMINISTRATIVOS Y PRIVADOS EN FUNCIÓN DE LA ENTIDAD CONTRATANTE. III. LOS CONTRATOS SUJETOS A REGULACIÓN ARMONIZADA Y LOS CONTRATOS ASIMILADOS. EL CONCEPTO DE PODER ADJUDICADOR. IV. NEGOCIOS Y RELACIONES JURÍDICAS EXCLUIDAS. DELIMITACIÓN GENERAL Y APLICACIÓN DE LOS PRINCIPIOS GENERALES DE LA LCSP. V. LOS CONVENIOS DE COLABORACIÓN CELEBRADOS ENTRE LAS ADMINISTRACIONES Y LAS ENTIDADES PÚBLICAS Y SU EXCLUSIÓN DE LA LCSP. VI. LOS CONTRATOS "IN HOUSE PROVIDING". VII. LA EXCLUSIÓN DE LOS CONTRATOS EN EL SECTOR DE LA DEFENSA. LA FALTA DE APLICACIÓN DE LOS PRINCIPIOS DE CONCURRENCIA Y TRANSPARENCIA EN EL ÁMBITO DE LOS CONTRATOS PÚBLICOS DE DEFENSA. LA NECESIDAD DE GARANTIZAR EL RESPETO DE LOS PRINCIPIOS DE LA CONTRATACIÓN PÚBLICA CON ALGUNAS ESPECIALIDADES. VIII. LOS CONTRATOS DE SERVICIOS Y SUMINISTRO PARA LA EJECUCIÓN DE PROYECTOS DE INVESTIGACIÓN.

\footnotetext{
${ }^{1}$ Profesor Titular de Derecho Administrativo de la Universidad de Castilla-la Mancha.
} 


\section{EL NUEVO ENFOQUE DE LA LEGISLACIÓN DE CONTRATOS}

Frente a la Directiva europea que incorpora a nuestro ordenamiento (Directiva 2004/18/CE de contratos públicos de obras, suministros y servicios) y otras legislaciones de nuestro entorno jurídico como la italiana ${ }^{2}$ y la francesa ${ }^{3}$, la Ley 30/2007 espańola opta por destacar desde el principio su ámbito subjetivo de aplicación y se intitula de forma menos precisa técnicamente como de "Contratos del Sector Público" ${ }^{4}$. En efecto, la nueva Ley de Contratos se define a sí misma como del Sector Público frente a la que viene a sustituir que se identificaba como de Contratos de las Administraciones Públicas.

La intención del legislador es superar el limitado enfoque de la LCAP de 1995 dirigido a "los contratos que celebren las Administraciones Públicas" (artículo 1.1) y basado en la figura del contrato administrativo, para sustituirlo por una más amplia regulación de la actividad contractual de todo el sector público español. García DE ENTERRÍA ya había advertido tras analizar el ámbito aplicativo de la LCAP que ésta no era una Ley de contratos administrativos y que la norma había sido adoptada, por influencia del Derecho comunitario, desde una óptica distinta de la tradicional en nuestro Derecho de contratos de la Administración 5 .

De esta forma, la LCSP se diseña y estructura teniendo en cuenta su aplicabilidad a todos los sujetos del sector público, lo que a juicio de la exposición de motivos de la norma (apartado II) permite dar una respuesta más adecuada a los problemas derivados de situar el régimen aplicable a los contratos no celebrados por Administraciones Públicas en un ámbito caracterizado por su indefinición, rasgo especialmente notorio en el caso de los contratos no sujetos a las directivas comunitarias. Así, la LCSP aproxima su ámbito de aplicación al de las normas comunitarias que incorpora al Dere-

2 El Decreto Legislativo de 12 de abril de 2006, n. ${ }^{\circ}$ 163, aprueba el Código de Contratos Públicos de obras, servicios y suministros en cumplimiento de las Directivas 2004/17/CE y 2004/18/CE (Gazzetta Ufficiale de 2 de mayo de 2006, suplemento ordinario n. ${ }^{\circ}$ 107/L).

${ }^{3}$ Código francés de Contratos Públicos, que entró en vigor el 1 de septiembre de 2006.

${ }^{4}$ A favor de la denominación de "Ley de Contratos Públicos" se pronuncia Gimeno Feliú, J.M., "Los sujetos contratantes: alcance del concepto de poder adjudicador en la Ley de Contratos del Sector Público", en AAVV (coordinación Moreno Molina, J.A.), La nueva Ley de Contratos del Sector Público y su aplicación por las Entidades locales, CEMCI, Granada, 2008.

5 "Ámbito de aplicación de la Ley”, en AAVV, Comentarios a la Ley de Contratos de las Administraciones Públicas (dirección Gómez-Ferrer Morant), Civitas, Madrid, 2. ${ }^{a}$ ed., 2004, p. 82. 
cho español, "incrementando la seguridad jurídica al eliminar remisiones imprecisas y clarificar las normas de aplicación, aumentando la eficiencia de la legislación al tomar en cuenta la configuración jurídica peculiar de cada destinatario para modular adecuadamente las reglas que le son aplicables".

El nuevo enfoque en la legislación de contratos públicos gira en torno a dos puntos. En primer lugar, se pretende la ampliación del ámbito subjetivo de aplicación de la ley reguladora de los contratos públicos, construyendo desde el inicio la ley de contratación pública como una ley del sector público en el sentido más amplio posible. En segundo lugar, se quiere con este nuevo planteamiento identificar nítidamente qué normas provienen de la regulación tradicional interna del contrato celebrado por Administraciones Públicas y cuáles tienen su origen en el Derecho comunitario: de esta forma, se acuña el concepto de "contratos sujetos a regulación armonizada" para designar a aquellos contratos que, por razón de la entidad contratante, su tipo y su cuantía se encuentran sujetos a las prescripciones comunitarias - a algunas de ellas, porque otras obligaciones derivadas del Derecho comunitario se extienden por la LCSP a todos los contratos celebrados por las Administraciones públicas: vgr. reglas sobre aptitud para contratar con el sector público, especificaciones técnicas, condiciones especiales de ejecución, procedimientos de adjudicación, criterios de valoración de las ofertas, etc...-

La Ley 30/2007 ha incorporado por fin de manera decidida el cambio de perspectiva que desde hace años había impuesto en este sector el Derecho Comunitario y que sin embargo nuestra legislación se resistía a asumir plenamente. Así se explica que la LCSP destaque desde su fundamental artículo 1 que el respeto a los principios generales de la contratación pública es el objetivo y finalidad primera de la norma, que persigue garantizar la libertad de acceso a las licitaciones, la publicidad y transparencia de los procedimientos, así como la no discriminación e igualdad de trato entre los candidatos.

Pero la LCSP también hace expresa referencia en el párrafo 2 del artículo 1 a que "es igualmente objeto de esta Ley la regulación del régimen jurídico aplicable a los efectos, cumplimiento y extinción de los contratos administrativos, en atención a los fines institucionales de carácter público que a través de los mismos se tratan de realizar". Pues bien, las prerrogativas o cláusulas exorbitantes de la Administración en los contratos administrativos se recogen en el Capítulo II del Título I del Libro IV de la LCSP —artículos 194 y 195-, con una ubicación sistemática mejor que la del TRLCAP que incluyó al artículo 59 del TRLCAP — precepto que se ha desdoblado ahora en los artículos 194 y 195 de la LCSP- en el Título III (con la imprecisa rúbrica de "Actuaciones relativas a la contratación") del Libro I de la Ley. 
Ahora bien, los principios de objetividad, transparencia, publicidad y no discriminación, basados en reglas nacionales y comunitarias de naturaleza constitucional, prevalecen hoy de forma incuestionable sobre cualquier otra función de la normativa sobre contratación. Estos principios son en nuestros días el fundamento de todas las reglas públicas sobre contratos públicos y se caracterizan por su transversalidad, ya que alcanzan y se manifiestan en todas las fases contractuales, preparatorias y ejecutorias - frente, por ejemplo, a las Directivas europeas sobre contratos o al Acuerdo Mundial sobre Contratación Pública de la OMC, que regulan casi exclusivamente las fases de preparación y adjudicación de los contratos-.

\section{LA TIPOLOGÍA DE ENTIDADES Y CONTRATOS EN LA LEY DE CONTRATOS DEL SECTOR PÚBLICO. LA NUEVA CATEGORIZACIÓN DE LOS CONTRATOS ADMINISTRATIVOS Y PRIVADOS EN FUNCIÓN DE LA ENTIDAD CONTRATANTE}

Una de las claves para la comprensión de la nueva Ley de Contratos del Sector Público radica sin duda en la tipología de las entidades contratantes. Según la categoría de que se trate tendrán que aplicar la Ley con diferentes niveles de intensidad y según sus regímenes contractuales. La LCSP combina, para la determinación de estos diferentes niveles de aplicación de la norma, criterios subjetivos (hay 3 categorías dentro de las entidades del sector público: las Administraciones públicas, los poderes adjudicadores que no tienen el carácter de Administraciones públicas y los restantes entes del sector público) con criterios objetivos, que serán objeto de análisis más adelante, y entre los cuales destacan sobre todo las clases de contratos que recoge la Ley (típicos, administrativos, mixtos, privados y contratos sujetos a regulación armonizada o no).

Pues bien, en la tipología de entidades y de contratos se apoya toda la estructura de la Ley. En cuanto a éstos, la Ley 30/2007 mantiene las categorías tradicionales en nuestro Derecho - pero que no se conocen en las Directivas comunitarias - de contratos administrativos y contratos privados de la Administración, así como la dualidad de regímenes jurídicos (de Derecho administrativo y de Derecho privado) para los contratos del sector público, precisando los supuestos en que se aplica uno u otro y las normas por las que se rigen.

Sin embargo, la regulación introduce una novedosa configuración de las categorías ya que la figura de los contratos administrativos se reserva exclusivamente a los celebrados por las Administraciones públicas. Para todos los 
entes, organismos y entidades del sector público que no reúnan la condición de Administración Pública (que define el apartado 2 del artículo 3 de la LCSP), los contratos que celebren se considerarán contratos privados (artículo 20.1).

Por ello, cuando los artículos 5 a 12 de la Ley de Contratos del Sector Público se ocupan de la delimitación de los tipos contractuales y definen, de acuerdo con la Directiva 2004/18, los distintos contratos (obras, concesión de obras públicas, gestión de servicios públicos, suministro, servicios y el nuevo contrato de colaboración entre el sector público y el sector privado) ya no se hace alusión a los contratos administrativos como hacía el artículo 5 del TRLCAP ("son contratos administrativos aquellos cuyo objeto directo, conjunta o separadamente, sea la ejecución de obras, la gestión de servicios públicos...”, letra a) del apartado 2 del artículo 5). Ahora se definen los tipos contractuales, que luego podrán dar lugar a contratos administrativos o a contratos privados.

En lo que se refiere a las Administraciones públicas, la regulación sigue a la del TRLCAP, aunque se precisa la definición de los contratos privados cuya categoría se pretende ampliar. En este sentido se atribuye expresamente carácter privado a los contratos de suscripción a revistas, publicaciones y acceso a bases de datos ${ }^{6}$.

El artículo 2 de la Ley establece en su apartado 1 que son contratos del sector público y quedan sometidos a la norma los contratos onerosos - elemento definidor clave-, "cualquiera que sea su naturaleza jurídica, que celebren los entes, organismos y entidades enumerados en el artículo 3". De acuerdo con ello, la LCSP excluye ahora del ámbito de aplicación de la LCSP las autorizaciones y concesiones sobre bienes de dominio público, "los contratos de explotación de bienes patrimoniales distintos a los definidos en el artículo 7", así como los contratos de compraventa, donación, permuta, arrendamiento y demás negocios jurídicos análogos sobre bienes inmuebles, valores negociables y propiedades incorporales, a no ser que recaigan sobre programas de ordenador y deban ser calificados como contra-

${ }^{6}$ La disposición adicional duodécima de la LCSP prevé unas normas especiales para la contratación del acceso a bases de datos y la suscripción a publicaciones. En concreto, establece que la suscripción a revistas y otras publicaciones, cualquiera que sea su soporte, así como la contratación del acceso a la información contenida en bases de datos especializadas, podrán efectuarse, cualquiera que sea su cuantía siempre que no tengan el carácter de contratos sujetos a regulación armonizada, de acuerdo con las normas establecidas en la LCSP para los contratos menores y con sujeción a las condiciones generales que apliquen los proveedores, incluyendo las referidas a las fórmulas de pago. El abono del precio, en estos casos, se hará en la forma prevenida en las condiciones que rijan estos contratos, siendo admisible el pago con anterioridad a la entrega o realización de la prestación, siempre que ello responda a los usos habituales del mercado. 
tos de suministro o servicios, que tendrán siempre el carácter de contratos privados y se regirán por la legislación patrimonial. En estos contratos no podrán incluirse prestaciones que sean propias de los contratos típicos regu-

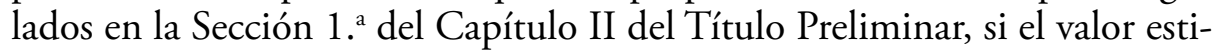
mado de las mismas es superior al $50 \%$ del importe total del negocio o si no mantienen con la prestación característica del contrato patrimonial relaciones de vinculación y complementariedad en los términos previstos en el artículo 25; en estos dos supuestos, dichas prestaciones deberán ser objeto de contratación independiente con arreglo a lo establecido en la Ley de Contratos.

Con arreglo a la legislación anterior, la jurisprudencia había interpretado que los contratos celebrados por la Administración pública que afectan a bienes patrimoniales tienen carácter jurídico privado si el objeto del contrato es ajeno a obras y servicios públicos ${ }^{7}$. En este sentido, la STS (Sala de lo Contencioso-Administrativo) de 20 de noviembre de 1996 declaró que tiene carácter civil el arrendamiento de una industria, la de bar cafetería, instalada en un teatro:

\begin{abstract}
"dado el carácter de bien patrimonial del objeto arrendado, la consideración de ingresos privados de sus rentas y la no condición de servicio público del bar-cafetería del "Teatro Romea”, propiedad del Ayuntamiento y que constituye tal objeto locaticio, sin que a ello se oponga el que en el contrato suscrito se califique a éste de administrativo, pues las cosas son lo que son y no lo que se las denomina”.
\end{abstract}

En relación con los contratos administrativos, el artículo 19 de la LCSP precisa que tendrán tal carácter los contratos siguientes, siempre que se celebren por una Administración pública:

a) Los contratos de obra, concesión de obra pública, gestión de servicios públicos, suministro, y servicios, así como los contratos de colaboración entre el sector público y el sector privado. No obstante, los contratos de servicios comprendidos en la categoría 6 del Anexo II y los que tengan por objeto la creación e interpretación artística y literaria y los de espectáculos comprendidos en la categoría 26 del mismo Anexo no tendrán carácter administrativo.

b) Los contratos de objeto distinto a los anteriormente expresados, pero que tengan naturaleza administrativa especial por estar vinculados al giro o tráfico específico de la Administración contratante o

7 Véase Gallego Córcoles, I., "Distinción entre contratos civiles y contratos administrativos" en Revista Práctica de Contratación Administrativa (julio 2004, pp. 41 y ss). 
por satisfacer de forma directa o inmediata una finalidad pública de la específica competencia de aquélla, siempre que no tengan expresamente atribuido el carácter de contratos privados conforme al párrafo segundo del artículo 20.1, o por declararlo así una Ley.

Los contratos administrativos especiales se siguen definiendo pues, como hacía el artículo 5 del TRLCAP, en base a su vinculación al giro o tráfico específico de la Administración contratante o por la satisfación de una finalidad pública de la específica competencia de aquélla. Sin embargo, la categoría de los contratos especiales va a perder mucha fuerza aplicativa como consecuencia de la amplia definición en la LCSP de los contratos típicos y, en especial, de la figura de los contratos de servicios, que se convierten con la nueva Ley en el cajón de sastre donde incluir las prestaciones de hacer que no sean obras o suministros.

La Junta Consultiva de Contratación Administrativa había señalado en su Informe 5/1996, de 7 de marzo, que es la referencia legal a la vinculación - y no a la pertenencia estricta — al giro o tráfico administrativo lo que permitía incluir en la categoría de los contratos administrativos especiales aquellos contratos que afecten al concreto interés público perseguido por la Administración de que se trate.

En relación con los contratos especiales, la LCAP de 1995 recogió la doctrina del Tribunal Supremo que había interpretado la noción de "servicio público" utilizada por la Ley de Contratos de 1965 para calificar el contrato como administrativo como "cualquier actividad que la Administración desarrolle para satisfacer el interés general atribuido a la esfera específica de su competencia", esto es, toda actividad "que se refiera al giro o tráfico específico del órgano administrativo que celebre el contrato" (sentencias del Tribunal Supremo de 16 de octubre y de 19 de mayo de 1996).

\section{LOS CONTRATOS SUJETOS A REGULACIÓN ARMONIZADA Y LOS CONTRATOS ASIMILADOS. EL CONCEPTO DE PODER ADJUDICADOR}

La nueva Ley de Contratos crea también la categoría de los contratos sujetos a regulación armonizada (SARA), que incluye a los contratos que superen los umbrales previstos por la Directiva 2004/18/CE.

La identificación de estos contratos se ajusta a lo establecido en la Directiva, con las siguientes matizaciones: por una parte, y en minoración de la caracterización de la norma comunitaria, el concepto no incluye los contra- 
tos de servicios de las categorías 17 a 27 del anexo $\mathrm{II}^{8}$, a los que la disposición comunitaria declara aplicables solo las normas sobre establecimiento de prescripciones técnicas y publicidad de las adjudicaciones: en la medida en que el ámbito de la exención supera con mucho al de la sujeción, se ha optado por dejarlos fuera de la categoría de "contratos sujetos a regulación armonizada" y establecer su sometimiento a las mismas reglas que éstos en los lugares pertinentes de la ley (artículos 104.1 —información sobre las condiciones de subrogación en contratos de trabajo- y 138.3 — referido a la publicidad de la adjudicación en los contratos de servicios comprendidos en las categorías 17 a 27 del Anexo II); por otra parte, y como prescripción extensiva respecto del derecho comunitario que no ha abordado todavía su regulación, se califican como contratos sujetos a regulación armonizada, en todo caso, a los contratos de colaboración entre el sector público y el sector privado, en atención a su complejidad, cuantía, y peculiar configuración.

La propia Ley de Contratos ofrece una lista negativa de contratos que no se consideran sujetos a regulación armonizada, cualquiera que sea su valor estimado:

a) Los que tengan por objeto la compra, el desarrollo, la producción o la coproducción de programas destinados a la radiodifusión, por parte de los organismos de radiodifusión, así como los relativos al tiempo de radiodifusión.

b) Los de investigación y desarrollo remunerados íntegramente por el órgano de contratación, siempre que sus resultados no se reserven para su utilización exclusiva por éste en el ejercicio de su actividad propia.

c) Los incluidos dentro del ámbito definido por el artículo 296 del Tratado Constitutivo de la Comunidad Europea que se concluyan en el sector de la defensa.

d) Los declarados secretos o reservados, o aquéllos cuya ejecución deba ir acompañada de medidas de seguridad especiales conforme a la legislación vigente, o en los que lo exija la protección de intereses esenciales para la seguridad del Estado. La declaración de secreto deberá hacerse, de forma expresa en cada caso, por el titular del

\footnotetext{
${ }^{8}$ Se trata de los servicios de hostelería y restaurante, de transporte por ferrocarril, de transporte fluvial y marítimo, de transporte complementarios y auxiliares, servicios jurídicos, servicios de colocación y suministro de personal, servicios de investigación y seguridad - excepto servicios de furgones blindados-, servicios de educación y formación profesional, servicios sociales y de salud, servicios de esparcimiento, culturales y deportivos y el cajón de sastre de "otros servicios".
} 
Departamento ministerial del que dependa el órgano de contratación en el ámbito de la Administración General del Estado, sus Organismos autónomos, Entidades gestoras y Servicios comunes de la Seguridad Social y demás Entidades públicas estatales, por el órgano competente de las Comunidades Autónomas, o por el órgano al que esté atribuida la competencia para celebrar el correspondiente contrato en las Entidades locales (véase la disposición adicional $2 .^{a}$ de la LCSP). La competencia para efectuar esta declaración no será susceptible de delegación, salvo que una ley expresamente lo autorice.

e) Aquéllos cuyo objeto principal sea permitir a los órganos de contratación la puesta a disposición o la explotación de redes públicas de telecomunicaciones o el suministro al público de uno o más servicios de telecomunicaciones.

Ahora bien, la significación de la nueva categoría es mucho menos importante en la LCSP que lo que anuncia su exposición de motivos (apartado IV.2) o lo que parece desprenderse de su ubicación sistemática y su regulación en el Título Preliminar, "Disposiciones Generales", de la Ley. De los tres tipos de sujetos que reconoce el artículo 3 de la LCSP, los contratos SARA no operan para las entidades del sector público del apartado 1 que no sean poderes adjudicadores (por la propia definición del artículo 13.1 de la Ley) y la categoría carece de verdadera trascendencia en relación con los contratos celebrados por las Administraciones públicas, que se consideren o no contratos SARA se someten al mismo régimen jurídico salvo en lo que se refiere a la publicidad comunitaria y al recurso especial en materia de contratación, que de una forma muy criticable sólo se contempla en la LCSP para los contratos SARA?

La diferenciación resulta operativa principalmente para los contratos celebrados por los poderes adjudicadores que no sean Administraciones. Para

9 El régimen jurídico que se deriva de la lectura sistemática del artículo 37 y de las distintas disposiciones de la Ley relativas a la adjudicación de los contratos (en particular, los artículos 27 y 135), permite concluir que la adjudicación provisional es una fase insuficientemente articulada en la LCSP para los contratos celebrados por las Administraciones públicas que no se consideren SARA, para los cuales, al no existir la posibilidad de interponer el recurso especial en materia de contratación, sólo cabe impugnar el acto administrativo de adjudicación provisional a través de un recurso administrativo de la Ley 30/92 o contencioso-administrativo de la Ley 29/98, ninguno de los cuales se adecua en sus plazos de interposición o resolución ni en sus características (efectos no suspensivos) al desarrollo procedimental del artículo 135 de la LCSP —como sí lo hace el recurso especial—. 
ellos el que celebren contratos sujetos o no sujetos a regulación comunitaria supone que su régimen jurídico o bien se asemejan en mucho al de los contratos administrativos (los celebrados por las Administraciones públicas en la nueva LCSP), o bien puedan someterse a un régimen flexible escapando de muchas de las normas jurídico-públicas de contratación. Pero para conseguir esta diferenciación, perseguida ya desde hace bastante tiempo en nuestro Derecho (baste ver las sentencias del TJCE condenatorias de nuestro país en materia de contratación pública ${ }^{10}$ ), no hacía falta esta construcción jurídica. Incluso la flexibilización de la regulación para los entes del sector público que no son Administraciones públicas pero sí han sido creados para satisfacer necesidades de interés general no industriales ni mercantiles, va más allá de la regulación anterior, que sometía a las entidades públicas empresariales estatales y sus asimiladas autonómicas o locales a la regulación prevista para los contratos administrativos.

Pero la mayor crítica a la nueva categoría de los contratos SARA debe ve nir desde el Derecho comunitario europeo, en el que se apoya teóricamente nuestro legislador para construir la figura y el mismo que está detrás de la definición recogida en los artículos 13 y siguientes de la LCSP. Si para el ordenamiento comunitario (Derecho originario y derivado y doctrina jurisprudencial del TJCE) los principios y las obligaciones aplicables a todos los contratos públicos deben ser en esencia las mismas, la distinción en nuestra LCSP entre contratos SARA y no SARA resulta muy cuestionable. En especial, cuando se observa cómo el legislador español justifica que el nuevo enfoque en la legislación de contratos públicos gira en torno a la identificación de las normas que "provienen de la regulación tradicional interna del contrato celebrado por Administraciones públicas y cuáles tienen su origen en el Derecho comunitario" y que con la positivación de los contratos SARA se pretende "permitir la modulación de la aplicabilidad de las normas de la Directiva a los diferentes contratos del sector público" pero también, de la misma forma, y por exclusión, el concepto sirve "para definir el conjunto de contratos respecto de los cuales el legislador nacional tiene plena libertad en cuanto a la configuración de su régimen jurídico" (apartado IV.2 de la exposición de motivos de la LCSP).

En este punto radica el error de base que luego llevará a la Ley a adoptar decisiones contrarias al Derecho comunitario. No existe libertad absoluta en los ordenamientos nacionales para regular la contratación del sector público

${ }^{10}$ Por todas, pueden verse las SSTJCE de 15 de mayo y 16 de octubre de 2003 y 13 de enero de 2005. 
por debajo de los umbrales europeos, o en los contratos en Espańa considerados no SARA. Al contrario, por encima o por debajo de las cuantías comunitarias — por cierto, bastante volátiles en los últimos años ${ }^{11}$ —, los principios a aplicar son los mismos: igualdad y no discriminación, transparencia publicidad y libre concurrencia.

La LCSP también acuña, incorporando la terminología comunitaria, el concepto de poder adjudicador, que identifica en el apartado 3 del artículo 3 considerando como tales a los siguientes entes, organismos y entidades:

a) Las Administraciones públicas.

b) Todos los demás entes, organismos o entidades con personalidad jurídica propia que no se consideran por la Ley como Administraciones públicas y que hayan sido creados específicamente para satisfacer necesidades de interés general que no tengan carácter industrial o mercantil, siempre que uno o varios sujetos que deban considerarse poder adjudicador de acuerdo con los criterios de este apartado 3 financien mayoritariamente su actividad, controlen su gestión, o nombren a más de la mitad de los miembros de su órgano de administración, dirección o vigilancia.

c) Las asociaciones constituidas por los entes, organismos y entidades mencionados en las letras anteriores.

En la peculiar tipología de los sujetos que establece la LCSP, dentro de las entidades del sector público (art. 3.1), resulta necesario singularizar 3 grandes categorías: Administraciones públicas (apartado 2 del artículo 3),

${ }^{11}$ La última de las modificaciones de las cuantías apareció en el DOUE L 317, del 5 de diciembre de 2007, que publicó el Reglamento (CE) 1422/2007, de la Comisión, de 4 de diciembre, por el que se modifican los umbrales de aplicación de los procedimientos de adjudicación de los contratos públicos a partir del 1 de enero de 2008. Este Reglamento dio lugar a la aprobación en España - lo que no debería haberse hecho por la naturaleza y eficacia directa del Reglamento comunitario- de la Orden EHA/3875/2007, de 27 de diciembre (BOE núm. 313 , de 31 de diciembre) y su corrección de errores publicada el 4 de febrero de 2008.

Hay que tener en cuenta que la disposición adicional decimocuarta de la Ley 30/2007 y la disposición final tercera de la Ley 31/2007 (como habían señalado anteriormente la disposición adicional segunda de la Ley de Contratos de las Administraciones Públicas, texto refundido aprobado por Real Decreto Legislativo 2/2000, de 16 de junio y la disposición final tercera de la Ley 48/1998, de 30 de diciembre, sobre procedimientos de contratación en los sectores del agua, la energía, los transportes y las telecomunicaciones), establecen que las cifras que en lo sucesivo se fijen por la Comisión Europea y se publiquen por Orden del Ministro de Hacienda, sustituirán a las que figuran en el texto de la misma. 
poderes adjudicadores que no tienen el carácter de Administraciones públicas y la categoría residual de "restantes entes del sector público" 12 .

La definición de la segunda de estas categorías se encuentra en el apartado 3 del artículo 3 LCSP por referencia a los criterios sentados en la Directiva 2004/18/CE y recogidos también en la letra h) del artículo 3.1, aunque, en este caso, el carácter residual de la referencia no opera en relación con todas las entidades enumeradas en las letras a) a g) del artículo 3.1 sino solo en relación con las que, dentro de esa enumeración, no tengan el carácter de Administraciones públicas, con lo que se define un ámbito más amplio. Además de por las normas del Libro I aplicables a todos los contratos del sector público, los entes integrantes de esta categoría se rigen por unas reglas bastante próximas a las de las Administraciones públicas en la preparación y adjudicación de contratos sujetos a la Directiva 2004/18 (artículos 27, 104, 105,173 y 174), y por unas normas con un menor nivel de exigencia en los restantes contratos (artículo 175).

Pero la LCSP sujeta también a su regulación, porque así lo exige la normativa europea sobre contratación pública, determinados contratos celebrados por sujetos no pertenecientes al sector público, como son los contratos de obras y servicios subvencionados en una parte relevante de su importe por entidades del sector público sujetas a la Directiva 2004/18/CE, definidos en el artículo 17 de la LCSP, y los contratos de obras que celebren los concesionarios de obras públicas, regulados en el artículo 250 de la Ley 30/2007. Así lo precisa el apartado 2 del artículo 2 de la nueva Ley, al definir el ámbito de aplicación de la misma.

La conexión con el sector público que se produce por la existencia de una financiación pública relevante o de la relación jurídica de concesión de obra pública antecedente, justifica su asimilación a los contratos del sector público y su regulación en el articulado de la propia Ley.

Las normas previstas para los contratos subvencionados sujetos a una regulación armonizada se aplicarán a aquéllos celebrados por particulares o por entidades del sector público que no tengan la consideración de poderes adjudicadores, en conjunción, en este último caso, con las restantes disposiciones de la LCSP que les sean de aplicación. Cuando el contrato subvencionado se adjudique por entidades del sector público que tengan la consideración de poder adjudicador, se aplicarán las normas de contratación previstas para estas entidades, de acuerdo con su naturaleza, salvo la relativa a la determinación de la competencia para resolver el recurso especial en

12 Sobre la compleja construcción del ámbito objetivo de la LCSP, puede verse GIMENO Feliú, J.M., "El nuevo ámbito subjetivo de aplicación de la Ley de Contratos del Sector Público: leyes y nombres”, RAP 176 (2008), pp. 9 y ss. 
materia de contratacióJ88n y para adoptar medidas cautelares en el procedimiento de adjudicación, que se regirá, en todo caso, por la regla establecida en el segundo párrafo del artículo 37.4.

Hay que recordar que el artículo 21 de la nueva Ley de Contratos establece que el orden jurisdiccional contencioso-administrativo será el competente para resolver las cuestiones litigiosas relativas a la preparación y adjudicación de los contratos sujetos a regulación armonizada, incluidos los contratos subvencionados. En este punto, no hay huída de la jurisdicción contencioso administrativa, como lamentablemente si se produce con el apartado 2 del artículo 21 de la nueva Ley de Contratos cuando establece que el orden jurisdiccional civil será el competente para resolver las controversias que surjan entre las partes en relación con la preparación y adjudicación de los contratos privados que se celebren por los entes y entidades sometidos a esta Ley que no tengan el carácter de Administración pública, siempre que estos contratos no estén sujetos a una regulación armonizada. Se resucita así la problemática de la dualidad de jurisdicciones apartándose la LCSP de la clásica teoría de los actos separables.

\section{NEGOCIOS Y RELACIONES JURÍDICAS EXCLUIDAS. DELIMITACIÓN GENERAL Y APLICACIÓN DE LOS PRINCIPIOS GENERALES DE LA LCSP}

La LCSP se aplica a todos los contratos celebrados por los sujetos pertenecientes al sector público que se definen en el artículo 3, exceptuados los supuestos que se enumeran en el artículo 4.

Los negocios y relaciones jurídicas excluidas (la rúbrica del artículo 4 LCSP, como lo era la del artículo 3 del TRLCAP, es más imprecisa técnicamente al hacer referencia a "negocios y contratos excluidos"), se recogen por la LCSP de forma similar, en líneas generales, a la regulación que hacía el TRLCAP, con las principales novedades de la definición de los convenios de colaboración (letra c), de la exclusión de los supuestos en los que una entidad del sector público es la que realiza la prestación objeto del contrato (letra m), de la doctrina del Tribunal de Justicia de las Comunidades Europeas recogida en relación con los denominados "contratos in house providing" (letra n), de la exclusión del ámbito de la ley de los negocios regulados en la legislación patrimonial, los cuales, frente al TRLCAP, se considera preferible extraerlos por completo de la legislación de contratos (letras o) ${ }^{13}$

\footnotetext{
13 Salvo la posible utilización de los principios de la ley para resolver las dudas y lagunas que pudieran presentarse (artículo 4.2 LCSP).
} 
y p), considerando su completa regulación en la Ley 33/2003, de 3 de noviembre, del Patrimonio de las Administraciones Públicas, y la nueva letra q), que, en línea con lo dispuesto por el artículo 83 de la Ley Orgánica 6/2001, de Universidades, deja fuera de la Ley los contratos de servicios y suministro celebrados por los Organismos Públicos de Investigación estatales y los Organismos similares de las Comunidades Autónomas que tengan por objeto prestaciones o productos necesarios para la ejecución de proyectos de investigación, desarrollo e innovación tecnológica o servicios técnicos, cuando la presentación y obtención de resultados derivados de los mismos esté ligada a retornos científicos, tecnológicos o industriales susceptibles de incorporarse al tráfico jurídico y su realización haya sido encomendada a equipos de investigación del Organismo mediante procesos de concurrencia competitiva.

Muchos de los supuestos del artículo 4 de la Ley 30/2007 recogen exclusiones contempladas en los artículos 12 a 18 de la Directiva 2004/18/CE, de 31 de marzo de 2004, sobre coordinación de los procedimientos de adjudicación de los contratos públicos de obras, de suministro y de servicios.

Los contratos, negocios y relaciones jurídicas excluidas de la aplicación de la Ley de Contratos se regularán por sus normas especiales, si bien se aplicarán los principios de la LCSP para resolver las dudas y lagunas que pudieran presentarse, como expresamente señala el apartado 2 del artículo 4 de esta norma.

Desde el pórtico de la nueva Ley de Contratos — artículo 1- y a lo largo de todo su texto (de forma que incluso se hace en muchas ocasiones reiterativa y redundante) el respeto a los principios generales de la contratación pública se presenta como el objetivo y finalidad primera de la norma, que persigue garantizar la libertad de acceso a las licitaciones, la publicidad y transparencia de los procedimientos, así como la no discriminación e igualdad de trato entre los candidatos. No podía ser de otra manera, pues así lo exigía el Derecho comunitario de los contratos públicos, de forma destacada gracias a la jurisprudencia del Tribunal de Justicia de la Unión Europea.

El Derecho español de los contratos públicos ya recogía algunos de estos principios generales como fundamento de su normativa, sobre todo tras la adaptación al Derecho comunitario europeo. El precepto clave en este sentido era el artículo 11 de la Ley de Contratos de las Administraciones Públicas.

Entre los principios generales de la contratación pública sobresale por encima de todos los demás el principio de igualdad y la prohibición de toda discriminación, que habrán de respetarse en todo caso y a lo largo del completo proceso selectivo. Pero junto al principio de igualdad y en íntima 
conexión con él se aplican en este ámbito los principios de publicidad, transparencia y concurrencia, notablemente reforzados con la reciente introducción de medios electrónicos y telemáticos en los procedimientos de licitación.

Además de estos principios, en la nueva Ley de Contratos se recogen, por influencia comunitaria, otros principios aplicables hoy a la contratación pública: se trata de los principios de confidencialidad, motivación de las decisiones, economía, eficiencia y eficacia, la consecución de objetivos sociales y la protección del medio ambiente.

En una lúcida doctrina, el Tribunal de Justicia de las Comunidades Europeas ha destacado que la obligación de respeto de los principios de objetividad, imparcialidad y no discriminación en la adjudicación de los contratos públicos se extiende no sólo a los contratos que caen dentro del ámbito de aplicación de las directivas comunitarias sobre contratación pública, el cual no deja de ser limitado (el artículo 7 de la Directiva 2004/18/CE fija el ámbito de aplicación de la misma estableciendo unos umbrales económicos) ${ }^{14}$, sino también a todos los contratos que celebren los órganos de contratación sujetos

${ }_{14}$ Reza así el citado precepto — tras la última modificación operada por el Reglamento n. ${ }^{\circ}$ 1422/2007 de la Comisión, de 4 de diciembre de 2007—: "La presente Directiva se aplicará a los contratos públicos que no estén excluidos en virtud de las excepciones previstas en los artículos 10 y 11 y en los artículos 12 a 18 y cuyo valor estimado, sin incluir el impuesto sobre el valor añadido (IVA), sea igual o superior a los umbrales siguientes:

a) 133.000 EUR, respecto de los contratos públicos de suministro y de servicios distintos de los contemplados en el tercer guión de la letra b) adjudicados por los poderes adjudicadores que sean una de las autoridades gubernamentales centrales que figuran en el anexo IV; por lo que se refiere a los contratos públicos de suministro adjudicados por dichos poderes adjudicadores que operen en el sector de la defensa, la presente disposición sólo se aplicará a los contratos relativos a los productos contemplados en el anexo V;

b) 206.000 EUR:

- respecto de los contratos públicos de suministro y de servicios adjudicados por poderes adjudicadores distintos de los contemplados en el anexo IV;

- respecto de los contratos públicos de suministro adjudicados por los poderes adjudicadores mencionados en el anexo IV y que operen en el sector de la defensa, cuando dichos contratos tengan por objeto productos distintos de los contemplados en el anexo V;

- respecto de los contratos públicos de servicios adjudicados por un poder adjudicador y que tengan por objeto servicios de la categoría 8 del anexo II A, servicios de telecomunicaciones de la categoría 5 cuyas posiciones en el CPV sean equivalentes a los números de referencia CPC 7524, 7525 y 7526 y/o servicios que figuren en el anexo II B.

c) 5.150.000 EUR, respecto de los contratos públicos de obras”. 
a las Directivas, ya que así lo exigen distintos preceptos del Tratado de la Comunidad Europea, tal y como han sido interpretados por el propio Tribunal.

De la jurisprudencia del alto Tribunal europeo los principios han pasado a las Directivas de contratación, que hoy los recogen de forma destacada (arts. 2 de la Directiva 2004/18/CE y 10 de la Directiva 2004/17/CE) y a la nueva Ley de Contratos española, que los ha elevado a su artículo 1 como fundamento de la normativa reguladora de la actividad contractual del sector público.

Pues bien, para que quedara todavía más claro, la Comisión Europea ha publicado una Comunicación interpretativa sobre el Derecho comunitario aplicable en la adjudicación de contratos no cubiertos o sólo parcialmente cubiertos por las Directivas sobre contratación pública (Diario Oficial $\mathrm{n}^{\circ} \mathrm{C}$ 179 de 01/08/2006).

El Tribunal europeo, tras comprobar cómo las Directivas sobre contratos no constituyen cuerpos uniformes y completos de normas sobre contratación pública, sostiene que los Estados siguen siendo libres para mantener o adoptar normas sustantivas y procedimentales que disciplinen los contratos públicos, pero, eso sí, "a condición de que se respeten todas las disposiciones aplicables del Derecho comunitario y, en particular, las prohibiciones derivadas de los principios consagrados por el Tratado"15. La sentencia del TJCE de 13 de octubre de 2005, asunto C-458/03, Parking Brixen GMBH, resulta muy ilustrativa cuando concluye que "pese a que, en el estado actual del Derecho comunitario, los contratos de concesión de servicios públicos se encuentran excluidos del ámbito de aplicación de la Directiva 92/50, las autoridades públicas que los celebren están obligadas no obstante a respetar, en general, las normas fundamentales del Tratado CE y, en especial, el principio de no discriminación por razón de la nacionalidad".

En la Sentencia Parking Brixen GMBH se analiza por el Tribunal europeo si la adjudicación de la gestión de unos aparcamientos públicos de pago constituye un contrato público de servicios o bien una concesión de servicios públicos a la que deben aplicarse las normas de la competencia, en particular la obligación de igualdad de trato y de transparencia. Una vez decidida por el Tribunal que se trataba de una concesión de servicios relativa a la gestión de un servicio público local (en el contrato en cuestión la retribución del prestador de servicios no procedía de la autoridad pública, sino de las cantidades abonadas por terceros para el uso del aparcamiento. Esta

15 Sentencia CEI y Bellini, de 9 de julio de 1987, Asuntos 27 a 29/86, Rec. 1987, F.J. 15, p. 3373. Véanse también las sentencias de 7 de diciembre de 2000, Teleaustria y Telefonadress, C-324/98, Rec. p. I-10745, apartado 60, y de 21 de julio de 2005, Coname, C-231/03, Rec. p. I-0000, apartado 16. 
modalidad de retribución implica que el prestador asume el riesgo de explotación de los servicios, lo cual es una característica de la concesión de servicios públicos ${ }^{16}$ ), se estudió por el Tribunal si la adjudicación de la misma sin licitación pública previa era compatible con el Derecho comunitario, en particular con los principios de libre prestación de servicios, libre competencia y prohibición de discriminación y las consecuentes obligaciones de igualdad de trato y de transparencia, así como con el principio de proporcionalidad, en caso de que recayese en una sociedad anónima constituida mediante la transformación de una empresa especial de un municipio, dándose la circunstancia de que el capital social de dicha sociedad anónima pertenecía en su totalidad al municipio en el momento de la adjudicación. Pues bien, para el máximo intérprete del Derecho comunitario europeo:

"El artículo 12 CE proclama la prohibición de toda discriminación por razón de nacionalidad. Entre las disposiciones del Tratado aplicables más específicamente a las concesiones de servicios públicos cabe destacar, en particular, el artículo $43 \mathrm{CE}$, cuyo primer párrafo prohíbe las restricciones a la libertad de establecimiento de los nacionales de un Estado miembro en el territorio de otro Estado miembro, y el artículo $49 \mathrm{CE}$, conforme a cuyo primer párrafo quedarán prohibidas las restricciones a la libre prestación de servicios dentro de la Comunidad para los nacionales de los Estados miembros establecidos en un país de la Comunidad que no sea el del destinatario de la prestación.

Según la jurisprudencia del Tribunal de Justicia, los artículos 43 CE y 49 CE constituyen una expresión particular del principio de igualdad de trato (véase la sentencia de 5 de diciembre de 1989, Comisión/Italia, C-3/88, Rec. p. 4035, apartado 8). La prohibición de discriminación por razón de nacionalidad constituye igualmente una expresión específica del principio general de igualdad de trato (véase la sentencia de 8 de octubre 1980, Überschär, 810/79, Rec. p. 2747, apartado 16). En la jurisprudencia relativa a las directivas comunitarias en materia de contratación pública, el Tribunal de Justicia ha precisado que el principio de igualdad de trato de los licitadores tiene por objeto que todos los licitadores dispongan de las mismas oportunidades al formular el contenido de sus ofertas, con independencia de su nacionalidad (véase en este sentido la sentencia de 25 de abril de 1996, Comisión/Bélgica, C-87/94, Rec. p. I-2043, apartados 33

${ }^{16}$ En este sentido, el artículo 1, apartado 4, de la Directiva 2004/18/CE del Parlamento Europeo y del Consejo, de 31 de marzo de 2004, sobre coordinación de los procedimientos de adjudicación de los contratos públicos de obras, de suministro y de servicios (que no resultaba de aplicación cuando se produjeron los hechos del caso de autos), establece que la "“concesión de servicios" es un contrato que presente las mismas características que el contrato público de servicios, con la salvedad de que la contrapartida de la prestación de servicios consista, o bien únicamente en el derecho a explotar el servicio, o bien en dicho derecho acompañado de un precio". 
y 54). De ello se deduce que el principio de igualdad de trato de los licitadores es aplicable a las concesiones de servicios públicos aun cuando no exista una discriminación por razón de nacionalidad.

Los principios de igualdad de trato y de no discriminación por razón de nacionalidad implican, en particular, una obligación de transparencia que permita que la autoridad pública concedente se asegure de que los mencionados principios son respetados. Esta obligación de transparencia que recae sobre dicha autoridad consiste en garantizar, en beneficio de todo licitador potencial, una publicidad adecuada que permita abrir a la competencia la concesión de servicios y controlar la imparcialidad de los procedimientos de adjudicación (véase en este sentido la sentencia Teleaustria y Telefonadress, antes citada, apartados 61 y 62).

Corresponde a la autoridad pública concedente apreciar, bajo el control de los tribunales competentes, la adecuación de las modalidades de licitación a las particularidades de cada concesión de servicios públicos. Sin embargo, la falta total de licitación en la adjudicación de una concesión de servicios públicos como la que es objeto del caso de autos no responde a los requisitos de los artículos $43 \mathrm{CE}$ y $49 \mathrm{CE}$ ni a los principios de igualdad de trato, no discriminación y transparencia.

Además, el artículo $86 \mathrm{CE}$, apartado 1, establece que los Estados miembros no adoptarán ni mantendrán, respecto de las empresas públicas y aquellas empresas a las que concedan derechos especiales o exclusivos, ninguna medida contraria a las normas del presente Tratado, especialmente las previstas en los artículos $12 \mathrm{CE}$ y $81 \mathrm{CE}$ a $89 \mathrm{CE}$, ambos inclusive.

De lo anterior se desprende que los Estados miembros no deben mantener en vigor una normativa nacional que permita la adjudicación de concesiones de servicios públicos sin licitación, puesto que tal adjudicación infringe los artículos $43 \mathrm{CE}$ o $49 \mathrm{CE}$, o vulnera los principios de igualdad de trato, no discriminación y transparencia" (fundamentos jurídicos 47 a 52).

\section{LOS CONVENIOS DE COLABORACIÓN CELEBRADOS ENTRE LAS ADMINISTRACIONES Y LAS ENTIDADES PÚBLICAS Y SU EXCLUSIÓN DE LA LCSP}

Uno de los supuestos de exclusión de la Ley de Contratos que más problemas ha planteado en la práctica de nuestras Administraciones públicas, principalmente por el uso extensivo y abusivo que se ha hecho de la figura, es el que contempla la letra c) del apartado 1 del artículo 4 de la LCSP, que especifica ahora la no aplicación de la Ley a:

"los convenios de colaboración que celebre la Administración General del Estado con las entidades gestoras y servicios comunes de la Seguridad Social, las Universidades Públicas, las Comunidades Autónomas, las Entidades locales, organismos autónomos y restantes entidades públicas, o los que celebren estos or- 
ganismos y entidades entre sí, salvo que, por su naturaleza, tengan la consideración de contratos sujetos a la LCSP”.

Con la redacción final del precepto ${ }^{17}$ se ha limitado el alcance de la excepción, con el fin de evitar una huida del derecho de los contratos por la vía de un uso indebido de los convenios. En este sentido, hay que recordar que en su redacción inicial en el Proyecto de Ley el precepto sometía a la legislación de contratos estos convenios de colaboración cuando "por su naturaleza y cuantía, tengan la consideración de contratos sujetos a regulación armonizada", lo que era ilógico pues el umbral debe ser irrelevante a estos efectos ${ }^{18}$. En efecto, la técnica del convenio debe ser interpretada restrictivamente sin que pueda ser utilizada cuando la prestación este comprendida en el ámbito de la aplicación de la Directiva 2004/18 o de la Ley de Contratos ${ }^{19,20}$.

Del tenor literal del precepto, así como de la redacción de la letra d) del citado artículo 4, que excluye de la aplicación de la Ley "los convenios que, con arreglo a las normas específicas que los regulan, celebre la Administración con personas físicas o jurídicas sujetas al derecho privado, siempre que su objeto no esté comprendido en el de los contratos regulados en esta Ley o en normas administrativas especiales", se desprende que el elemento decisivo que permitirá considerar o no sujetos a la LCSP los convenios celebrados por las administraciones será el que su contenido sea propio de cualquiera de los contratos definidos por la Ley (artículos 6 a 12), tipos que además se definen ahora en forma muy amplia, por influencia del Derecho comunitario - baste tener en cuenta el nuevo y omnicomprensivo concepto

${ }_{17}$ Tras la enmienda número 153 del Grupo Parlamentario Socialista del Congreso, BOCD 29 de marzo de 2007, serie A. núm. 95-22, p. 228.

18 Gimeno Feliu, J.M., La nueva contratación pública europea y su incidencia en la legislación española. (La necesaria adopción de una nueva ley de contratos públicos y propuestas de reforma), Civitas, Madrid, 2006, p. 136.

19 Véase Carbonell Porras, E., "El título jurídico que habilita el ejercicio de la actividad de las sociedades mercantiles estatales de infraestructuras viarias. ¿Convenio o contrato administrativo?”, en libro col. Estudios de Derecho Público Económico, Civitas, Madrid, 2003, pp. 393-394 y Bernal Blay, M.A., "Las encomiendas de gestión excluidas de la Ley de Contratos de las Administraciones Públicas: una propuesta de interpretación del artículo 3.1 letra I TRLCAP”, Revista Española de Derecho administrativo, núm. 129, año 2006, pp. 77 a 90.

${ }^{20}$ Uno de los supuestos que recoge la propia Ley en que se puede utilizar la figura del convenio de colaboración es el previsto en el apartado 5 de la disposición adicional 2. ${ }^{a}$ que regula la posibilidad de que se concierten convenios de colaboración en virtud de los cuales se encomiende la gestión del procedimiento de contratación a las Diputaciones provinciales o a las Comunidades autónomas de carácter uniprovincial. 
del contrato de servicios ("prestaciones de hacer consistentes en el desarrollo de una actividad o ditigidas a la obtención de un resultado distinto de una obra o un suministro") o la definición de los contratos de gestión de servicios públicos, que analizaremos enseguida-

En efecto, hay que tener en cuenta que, con la LCSP, por medio de los contratos de gestión de servicios públicos pueden ser prestados todos los servicios de competencia de la Administración siempre que sean susceptibles de explotación por particulares (apartado 1 del artículo 251). En este punto la nueva Ley introduce una novedad relevante, pues amplía notablemente la posible utilización de la figura que antes estaba limitada a los servicios "de contenido económico que sean susceptibles de explotación por empresarios particulares" (artículo 155.1 del TRLCAP).

Con la nueva regulación se permite la contratación y la encomienda de prestación de servicios a particulares y no sólo a empresas y ya no es necesario además para que el servicio público tenga carácter económico. Como bien apuntaba la diputada MALARET en el debate para la ratificación de la ponencia designada para informar el Proyecto de Ley de Contratos del Sector Público ${ }^{21}$, la nueva definición del contrato de gestión de servicios públicos debe permitir evitar el recurso al convenio de colaboración, que en la actualidad constituye una de las graves patologías del sistema español de colaboración público-privada.

La problemática relativa a los convenios de colaboración celebrados por la Administración es ciertamente complicada a causa, sobre todo, de la ausencia de una definición legal de los mismos, e incluso de un concepto doctrinal netamente perfilado sobre su naturaleza ${ }^{22}$. Como recuerda la sentencia del Tribunal Supremo, Sala 3. ${ }^{a}$, Sección 4. ${ }^{a}$, de 18 de febrero de 2004 (LA LEY JURIS 943/2004):

"Sin intención de hacer un repaso exhaustivo de dicho concepto, es evidente que un sector de la doctrina científica parte de la idea de que la auténtica naturaleza de un Convenio de carácter administrativo, como categoría diferente al contrato propiamente dicho, supone la existencia de un elemento transaccional que a su vez implica la preexistencia de una relación jurídica, sea de origen voluntario o impuesta por la Ley, con la misma Administración, de suerte que el Convenio afecta de alguna forma a la medida y extensión de las obligaciones

${ }^{21}$ Diario de Sesiones del Congreso de los Diputados de 20 de junio de 2007, n. ${ }^{\circ}$ 852, p. 15.

${ }^{22} \mathrm{Al}$ respecto pueden verse los trabajos de ÁviLA OrIve (Los convenios de colaboración excluidos de la Ley de Contratos de las Administraciones Públicas, Civitas, Madrid, 2002) y Bustillo Bolado (Convenios y contratos administrativos: transacción, arbitraje y terminación convencional de los procedimientos, Aranzadi, Pamplona, 2004). 
derivadas de dicha relación jurídica (los convenios urbanísticos, expropiatorios y fiscales serían un buen ejemplo de ello). También se le ha contemplado desde el punto de vista de la contraposición entre una relación bilateral —-con recíprocos derechos y obligaciones — y la de carácter plurilateral y asociativo —-lo que supone hasta cierto punto el trasplante de conceptos del Derecho Privado- que conjunta actividades de la Administración y de los administrados para el cumplimiento de una común finalidad de interés público. Y no faltan tendencias como la apuntada en la ya antigua sentencia de este Tribunal de 8 de marzo de 1990, citada por la recurrida, que asocian la idea del contrato de gestión de un servicio público con la figura del empresario, negándole esta condición al concierto de que se trate si la idea de empresa y empresario no se halla presente en el mismo.

En la actualidad se suele aplicar sin dificultad el concepto de Convenio, como figura de negocio jurídico sustraído a las reglas legales aplicables al contrato administrativo, al tipo de conciertos celebrados por la Administración con la finalidad mencionada en primer lugar, e igualmente la jurisprudencia de esta Sala admite la existencia de los convenios de colaboración, o cooperación, para el mejor desarrollo y cumplimiento de una finalidad de carácter público estipulados entre entidades de este carácter, e incluso entre entidades de Derecho Público y sociedades privadas, gestoras de dichos servicios, siempre que ya figuren creadas e integradas en la propia organización de tales entidades públicas, de manera que el ente correspondiente viene a canalizar a través de las organizaciones instrumentales creadas dentro de su misma organización el cumplimiento del interés público que se trata de satisfacer (sentencia de 4 de julio de 2003, precisamente referida a un pleito procedente del Tribunal Superior de Justicia de Cataluña); mas cuando se trata de los denominados Convenios de colaboración que celebre la Administración con personas físicas o jurídicas sujetas al derecho privado para la satisfacción de un interés público [artículo $3.1 \mathrm{~d}$ ) de la Ley 13/1995 y de su Texto Refundido de 16 de junio de 2000] la doctrina jurisprudencial entiende que han de someterse a los principios de publicidad, competitividad e igualdad de oportunidades que inspiran tales disposiciones y que el artículo 11 consagra de una manera explícita (sentencias de 17 de octubre de 2000, 12 de enero de 2001 y 20 de diciembre de 2002), siempre que el objeto de los mismos coincida con el de los contratos regulados en dichas Leyes o en normas administrativas de carácter especial, como con respecto a la encomienda de gestión - -sea de carácter material o de prestación de servicios- recuerda el artículo 15 de la Ley de 26 de noviembre de 1992.

Consecuentemente no ha de ser la denominación que las partes intervinientes otorguen al negocio objeto de controversia la que determine el régimen jurídico que ha de regularlo, sino la real naturaleza del mismo la que ha de imponer o permitir prescindir de los principios mencionados. Y así ocurre (sentencias de 12 de marzo y 13 de octubre de 1999) que la inexistencia de contraprestación pecuniaria, dotando de carácter esencialmente gratuito al Convenio celebrado, o la concurrencia de supuestos excepcionales previstos en la normativa entonces vigente (Decreto 1005/1974, hoy derogado) pueden permitir prescindir de las exigencias impuestas por el artículo 11 aun cuando se trate de conciertos de co- 
laboración celebrados con personas particulares, físicas o jurídicas, que tengan por objeto algunas de las materias recogidas en el artículo $5 .^{\circ}$ de la Ley de Contratos del Estado; pero ello no quiere decir que fuera de tales supuestos excepcionales quepa obviar su cumplimiento mediante la utilización de la fórmula 'Convenio de colaboración’ en lugar de la de contrato administrativo” (F.J. 4).

Pero la sentencia citada también recuerda la importancia en la actualidad de las obligaciones, reforzadas por el Derecho comunitario de la contratación pública, de respetar en todo caso los principios de competitividad, publicidad y libre concurrencia, que constituye una aplicación al campo de la contratación administrativa de la igualdad proclamada por el artículo 14 de la Constitución, y que han sido recogidas en las directivas europeas en materia de contratos públicos,
"siendo procedente recordar que el incumplimiento puntual de las menciona- das en primer y último lugar dio lugar a la condena del Estado espańol en sendas resoluciones del Tribunal de Justicia de Luxemburgo (sentencias de 15 de mayo y 16 de octubre de 2003), motivando la modificación operada por la Ley 62/2003 al dar una nueva redacción al apartado 1 del artículo 2 de la Ley de Contratos refundida en 16 de junio de 2000, a la disposición adicional Sexta, e introduciendo nuevos apartados en su articulado. Y si bien es verdad que las modificaciones se refieren únicamente a los contratos celebrados por entidades de derecho público y sociedades de derecho privado creadas para satisfacer específicamente necesidades de interés general, que no tengan carác- ter industrial o mercantil, en las que concurra alguno de los requisitos especial- mente indicados y otorguen determinados contratos cuyo importe supere las cifras allí expresadas, también lo es que en el caso que nos ocupa el Convenio celebrado lo ha sido entre la Comunidad Autónoma y una asociación de carác- ter particular, encontrándose en todo caso sujeto a las prescripciones de la Ley antecitada (artículo $1 .^{\circ}$ ).
Lo que a nuestro supuesto afecta es que en ambas resoluciones - especial- mente en la de 16 de octubre - se insiste en la necesidad de que las entidades adjudicadoras observen fielmente en la contratación pública los principios que antes hemos mencionado, sin otras excepciones que las que se deriven del esta- blecimiento del régimen uniforme comunitario en las Directivas correspondien- tes" (F.J. 5).

Partiendo de lo anteriormente razonado el TS llega a la conclusión de que a través de un denominado Convenio de colaboración, concertado de modo directo y sin previo expediente que posibilite la concurrencia de otros posibles interesados que reúnan las condiciones de una oferta pública que no se ha formulado, el Departamento de Agricultura, Ganadería y Pesca de la Generalidad de Cataluña ha concertado con una entidad privada, consti- 
tuida casi de modo simultáneo y para la consecución de unos fines que se solapan con los que va a perseguir la unión resultante de ese Convenio, la prestación conjunta de un servicio de interés público que se considera de vital importancia para la provincia de Lérida, que supone importantes prestaciones materiales y pecuniarias y el otorgamiento a esa entidad privada de la facultad de proyectar y promover planes voluntarios y obligatorios de erradicación de enfermedades, realización de controles sistemáticos sanitarios en granjas y establecimientos porcinos, emisión de informes técnicos y certificados sanitarios, o cualesquiera otras actividades que le sean encomendadas por el Departamento correspondiente; y también la utilización del laboratorio oficial de Sanidad Ganadera y disposición conjunta del personal oficial adscrito, con la consiguiente facturación de los servicios, a cambio de una aportación pecuniaria que implica el sufragio de los gastos que ocasionen las actuaciones derivadas del Convenio suscrito. Por ello, "no cabiendo dudar que el objeto del concierto pactado se halla directamente vinculado a la actividad específica de la Administración Pública contratante y satisface de manera directa una finalidad pública de la propia competencia de ésta, ha de concluirse igualmente que se encuentra incluido en el apartado b) del artículo $5^{\circ}$ de la Ley de Contratos del Estado y que no puede equipararse a los Convenios de colaboración con particulares a que se refiere el apartado d) del artículo $3 .^{\circ}$ de la misma Ley, a los efectos de dispensa de someterse a los principios establecidos en su artículo 11" (F.J. 6).

También acude al Derecho comunitario de la contratación pública para fundamentar su fallo la sentencia del Tribunal Supremo, Sala Tercera, Sección 4. ${ }^{a}$, de 22 de abril de 2005 (LA LEY JURIS: 1505/2005), que concluye que ante una sociedad mixta como la del caso de autos no cabe entender existente una gestión directa del servicio sino una indirecta y que la suscripción de un Convenio interadministrativo incorporando a nuevos municipios como beneficiarios de la gestión del ciclo integral del agua en sus respectivos términos municipales por una sociedad mixta creada con un objeto limitado a un término municipal constituye una conducta elusiva del respeto a los principios de libertad de competencia y transparencia reiteradamente manifestados como esenciales.

La sentencia citada recuerda que las sociedades mercantiles bajo control público en mayor o menor grado no pueden ser excluidas del ámbito de aplicación de las directivas sobre contratos públicos (sentencias del Tribunal de Justicia de 10 de noviembre de 1998, asunto 460/1996 (LA LEY JURIS. 791558/1998), y 1 de febrero de 2001, asunto 237/1999 (LA LEY JURIS. $640866 / 2001$ ) al entender que no es la forma jurídica sino el objetivo el elemento fundamental a considerar. Teniendo en cuenta que el concepto de "organismo de derecho público" en el Derecho comunitario debe recibir 


\section{una interpretación funcional por lo que cabe una interpretación amplia, queda patente para el TS que:}

"bajo tal marco no resulta forzado pretender que la sociedad mixta habría de integrarse en el concepto de empresa pública en que los poderes públicos pueden ejercer directa o indirectamente, una influencia dominante por razón de la propiedad, de la participación financiera o de las normas que la rigen. La Directiva 80/723/CEE de la Comisión de 25 de junio de 1980, relativa a la transparencia de las relaciones financieras entre los Estados Miembros y las empresas públicas presume que hay influencia dominante cuando: a) poseen la mayoría del capital suscrito de la empresa; o b) disponen de la mayoría de los votos inherentes a las participaciones emitidas por la empresa; o c) pueden designar a más de la mitad de los miembros del órgano de administración, de dirección o de vigilancia de la empresa. Es cierto que aquí concurren los supuestos a) y c) que pueden ser considerados aisladamente pero, ya anticipamos que falla el esencial c) que rige la vida societaria.

Cuestión esta última absolutamente primordial para clarificar la interpretación que debe darse al art. 155.2 LCAP a los puros efectos litigiosos. Resulta absurdo e ilógico que unas Directivas dictadas para garantizar la transparencia administrativa como uno de los valores inherentes a la libertad de concurrencia pueda ser invocada justamente para eludirla así como que se pretenda una interpretación irracional del conjunto de normas locales expuestas en los párrafos precedentes. La ampliación del objeto societario de la empresa mixta como paso previo a la suscripción del Convenio interadministrativo para prestar el servicio de agua potable y alcantarillado en otro municipio, comporta una auténtica desnaturalización del objeto inicial de la empresa para la que, recordemos de nuevo, se llevó a cabo un concurso público para seleccionar al socio privado que, en unión del Ayuntamiento de Torrente, constituirá una empresa mixta para gestionar el servicio público del agua en el término municipal de Torrente. Si la publicidad y la concurrencia fueron garantizadas al constituirse la empresa mixta, dichos principios deben ser también respetados en cualquier modificación ulterior encaminada a la ampliación de la gestión de un servicio público. Se trata de evitar el establecimiento de facto de una posición de dominio en la actividad a favor de la empresa adjudicataria inicial mediante la publicidad y concurrencia exigida por el ordenamiento.

Nada impide que a través de un convenio de colaboración un ente local pueda asumir la gestión directa de los servicios públicos de otro ente local. Sin embargo es preciso respetar las normas reguladoras de la materia de que se trate, en este caso los principios de la contratación pública más arriba referenciados, cuando el sujeto que asume los citados servicios no lo hace directamente sino a través de la gestión indirecta lo que acontece con las empresas mixtas.

Distintas Corporaciones locales entre sí pueden constituir consorcios como forma de prestación del servicio de abastecimiento de agua o incluso asociarse con entes privados. En tal caso el Consorcio así creado tendrá naturaleza de ad- 
ministración pública, será quien gestione el servicio público por medio de alguna de las formas previstas en la legislación administrativa y sustituirá a los entes consorciados (art. 40 RSCL). También puede crear Mancomunidades como entes que tengan por objeto la prestación de servicios públicos pero contraviene las normas de contratación pública la suscripción de un Convenio interadministrativo como el aquí controvertido.

Significa, por tanto, que ante una sociedad mixta como la aquí constatada no cabe entender existente una gestión directa del servicio sino una indirecta. La suscripción de un Convenio interadministrativo incorporando a nuevos municipios como beneficiarios de la gestión del ciclo integral del agua en sus respectivos términos municipales por una sociedad mixta creada con un objeto limitado al término municipal de Torrente constituye una conducta elusiva del respeto a los principios de libertad de competencia y transparencia reiteradamente manifestados como esenciales" (F.J. 5 y 6 ).

En su recurso contra España origen de la STJCE de 13-1-2005, la Comisión denunciaba que el Texto Refundido de la Ley de Contratos española excluía incorrectamente de su ámbito de aplicación los convenios de colaboración que celebre la Administración General del Estado con la Seguridad Social, las Comunidades Autónomas, las entidades locales, sus respectivos organismos autónomos y las restantes entidades públicas o que celebren cualesquiera de estos organismos entre sí. A su juicio, esta exclusión absoluta constituía una adaptación incorrecta del Derecho interno a las Directivas 93/36 y 93/37, puesto que algunos de estos convenios pueden tener la misma naturaleza que los contratos públicos comprendidos en el ámbito de aplicación de éstas.

La Comisión invocaba la definición de contrato contenida en el artículo 1, letra a), de las Directivas 93/36 y 93/37 y la jurisprudencia del Tribunal de Justicia según la cual, para determinar la existencia de un contrato, es necesario comprobar si ha existido un convenio entre dos personas distintas (sentencia de 18 de noviembre de 1999, Teckal, C-107/98, Rec. p. I-8121, apartado 49). En consecuencia, estimaba que, habida cuenta de los anteriores elementos, los acuerdos de colaboración interadministrativos pueden ser contratos en el sentido de las Directivas comunitarias sobre contratos públicos.

Según la definición contenida en el artículo 1 de la Directiva 2004/18/ $\mathrm{CE}$, un contrato público de suministro o de obras supone la existencia de un contrato a título oneroso celebrado por escrito entre uno o varios operadores económicos y uno o varios poderes adjudicadores, en el sentido del artículo 1, apartado 9, de dicha Directiva y que tenga por objeto la compra de productos o la ejecución de determinado tipo de obras.

Conforme al artículo 1 de la Directiva basta, en principio, con que el contrato haya sido celebrado entre, por una parte, un ente territorial y, por 
otra, una persona jurídicamente distinta de éste. Sólo puede ser de otra manera en el supuesto de que, a la vez, el ente territorial ejerza sobre la persona de que se trate un control análogo al que ejerce sobre sus propios servicios y esta persona realice la parte esencial de su actividad con el ente o los entes que la controlan (sentencia Teckal, antes citada, apartado 50).

Para el Tribunal europeo de Justicia, habida cuenta de la identidad de los elementos constitutivos de la definición de contrato en las Directivas 93/36 y 93/37, a excepción del objeto del contrato considerado, procede aplicar la solución adoptada así en la sentencia Teckal, antes citada, a los acuerdos interadministrativos a los que se aplica la Directiva 93/37. En consecuencia, "dado que excluye a priori del ámbito de aplicación del Texto Refundido las relaciones entre las Administraciones Públicas, sus organismos públicos y, en general, las entidades de Derecho público no mercantiles, sea cual sea la naturaleza de estas relaciones, la normativa española de que se trata en el caso de autos constituye una adaptación incorrecta del Derecho interno a las Directivas 93/36 y 93/37" (apartado 40 de la STJCE de 13-1-2005).

En otra sentencia posterior del Tribunal de Justicia de las Comunidades Europeas, de 18 de enero de 2007, asunto C 220/05, se discutió sobre el convenio del Ayuntamiento de Roanne (Francia) con una sociedad mercantil de capital mixto (SEDL) para la creación de un centro de ocio en tramos sucesivos. El primer tramo comprendía la construcción de un centro multicines y de locales comerciales para su cesión a terceros, así como de instalaciones que habrán de revertir a la entidad adjudicataria (un aparcamiento, vías de acceso y espacios públicos). Los tramos posteriores, que implicaban la firma de nuevas cláusulas, consistían esencialmente en la construcción de otros locales comerciales o de servicios y de un hotel. Conforme a la introducción del convenio, el municipio de Roanne pretende con esta operación revitalizar un sector urbano poco valorizado y favorecer el desarrollo del ocio y el turismo. En virtud del artículo 2 del convenio, se atribuye a la SEDL, entre otras cosas, la función de proceder a adquisiciones inmobiliarias, convocar un concurso de arquitectura o ingeniería, encargar la realización de estudios, efectuar obras de construcción, elaborar y mantener actualizados determinados documentos contables y de gestión, recabar fondos y prever medios eficaces para posibilitar la comercialización de las obras, así como garantizar de modo general la gestión y la coordinación del proyecto y la información del municipio.

El TJCE concluye en su sentencia de 18-1-2007 que un convenio mediante el cual una primera entidad adjudicadora encarga a una segunda entidad adjudicadora la realización de una obra constituye un contrato público de obras con independencia del hecho de que se prevea o no que la 
primera entidad adjudicadora sea o pase a ser a propietaria de la totalidad o de parte de dicha obra. Señala así el Tribunal que para determinar si el objeto principal del convenio es la ejecución de una obra, carece de relevancia el que la SEDL no ejecute directamente las actividades de obra, sino que las encargue a subcontratistas ${ }^{23}$.

El alto Tribunal europeo recuerda que la Directiva comunitaria sobre contratos de obras no contiene disposiciones que permitan dejarla inaplicada en los contratos públicos de obras celebrados entre dos entidades adjudicadoras, aun suponiendo que la segunda entidad se vea obligada a subcontratar el valor total del mercado con sucesivos contratistas y a aplicar, a tal efecto, los procedimientos de adjudicación de contratos públicos previstos en la Directiva.

En el asunto se aplicó también la jurisprudencia europea sobre los denominados "contratos in house", que analizaremos en detalle a continuación. Ahora bien, en este caso resultaba claro que el hecho de que la SEDL sea una sociedad mercantil de capital mixto en la que se da participación privada excluye que pueda considerarse que el municipio de Roanne ejerce sobre ella un control análogo al que ejerce sobre sus propios servicios.

La más reciente sentencia del TJCE de 18 de diciembre de 2007, asunto C-220/06, analiza el convenio de colaboración — celebrado por tiempo indefinido- para la prestación de servicios postales y telegráficos entre el Ministerio español de Educación, Cultura y Deporte y la Sociedad Estatal

${ }^{23}$ El Tribunal europeo de Justicia ha venido pronunciándose en los últimos años sobre la necesaria relación entre la normativa urbanística y la de contratación pública, entendiendo así en su sentencia de 12 de julio de 2001 (LA LEY JURIS. 8625/2001) que "la adjudicación a un particular de un plan de urbanización que permite a su titular la realización directa de una obra pública, es un contrato de obra y ha de respetarse en cualquier caso la normativa comunitaria sobre contratación administrativa" (en esta importante sentencia el TJCE resolvió sendos recursos interpuestos contra los acuerdos del Ayuntamiento de Milán, mediante los cuales se aprobó un programa de obras denominado "proyecto Scala 2001", que incluía entre otras actuaciones la construcción de un nuevo teatro en la zona llamada de la "Bicocca").

Como ha señalado interpretando la citada STJCE Gimeno Feliú, es el concepto funcional de obra pública lo que atrae el régimen de la contratación pública a las obras de urbanización que viene obligados a ejecutar por imperativo legal en los sistemas de actuación indirecta por cuanto convergen todas las notas para su consideración de obra pública ("El urbanismo como actividad económica y mercado público: la aplicación de las normas de contratación pública”, $R A P$ n. ${ }^{\circ} 173$ (2007), p. 75).

En base a esta jurisprudencia el TSJ de la Comunidad Valenciana concluyó que la relación jurídica que se va a establecer entre la Administración y el agente urbanizador, por razón de la concesión del PAU, es de naturaleza contractual (sentencias de 1 de octubre de 2002, n. ${ }^{\circ}$ 1322/2002 - Sala de lo Contencioso-Administrativo, Sección 1. -; y de 5 de febrero de 2003, n. ${ }^{\circ}$ 156/2003 —Sala de lo Contencioso-Administrativo, Sección 1. -, (LA LEY JURIS $1358682 / 2002$ y $1505509 / 2003$, respectivamente). 
Correos y Telégrafos, S.A., sociedad que es el proveedor del servicio postal universal en España.

En el proceso judicial, el Gobierno español alegó que, debido a su carácter instrumental y no contractual, el convenio de colaboración no podía estar sujeto a las normas en materia de adjudicación de contratos públicos; de acuerdo con su argumentación, Correos no tiene ninguna posibilidad de negarse a celebrar un convenio de colaboración como el controvertido en autos, sino que debe aceptarlo obligatoriamente.

Sin embargo, para el Tribunal europeo, tan sólo en el supuesto de que el convenio de colaboración fuera en realidad un acto administrativo unilateral que impusiera obligaciones exclusivamente a cargo de Correos, acto que se apartaría sensiblemente de las condiciones normales de la oferta comercial de dicha sociedad, podría llegarse a la conclusión de que tal convenio no está sujeto a las normas comunitarias en materia de adjudicación de contratos públicos. El mero hecho de que Correos no disponga de libertad alguna ni en lo que atańe a la aceptación y ejecución de los encargos del Ministerio ni en cuanto a la tarifa aplicable a los servicios que presta no puede tener como consecuencia automática el que no se haya celebrado ningún contrato entre ambas entidades. En efecto, tal situación no es necesariamente diferente de la que existe cuando un cliente privado quiere utilizar los servicios de Correos que forman parte del servicio postal universal, puesto que del propio cometido del proveedor de este servicio se desprende que, en tal supuesto, también está obligado a prestar el servicio solicitado, y ello, en su caso, a tarifas fijas o, de todos modos, a tarifas transparentes y no discriminatorias. Pues bien, no cabe duda alguna de que tal relación debe calificarse de contractual.

En cuanto a la tesis del Gobierno español según la cual el convenio de colaboración no puede estar sujeto a las normas que regulan los contratos públicos debido al hecho de que se trata de una situación "in house", también es rechazada por el TJCE ya que un convenio de colaboración como el controvertido no cumple el segundo de los requisitos mencionados exigidos por la jurisprudencia europea al respecto (que dicha entidad realice la parte esencial de su actividad con la Administración que la controla) y no puede, por ello, quedar al margen de la aplicación de las normas enunciadas en los artículos $12 \mathrm{CE}, 43 \mathrm{CE}$ y $49 \mathrm{CE}$, así como de los principios generales de los que constituyen expresión específica. Tanto estas normas del máximo rango en el Derecho comunitario, como los principios de igualdad de trato, no discriminación por razón de la nacionalidad y transparencia, deben interpretarse en el sentido de que se oponen a una normativa como la espańola que permite que las Administraciones públicas, actuando al margen de las normas de adjudicación de los contratos públicos, 
"encarguen la prestación de servicios postales no reservados con arreglo a la Directiva 97/67 a una sociedad anónima pública de capital íntegramente público y que es el proveedor del servicio postal universal en dicho Estado, siempre que los convenios a los que tal normativa se aplique

- no alcancen el umbral pertinente según lo previsto en el artículo 7, apartado 1, de la Directiva 92/50 y

- no constituyan, en realidad, un acto administrativo unilateral que imponga obligaciones exclusivamente a cargo del proveedor del servicio postal universal y que se aparte sensiblemente de las condiciones normales de la oferta comercial de este último,

extremo cuya verificación corresponde al órgano jurisdiccional remitente" (apartados 87 y 88 de la STJCE de 18-12-2007).

\section{LOS CONTRATOS "IN HOUSE PROVIDING"}

El artículo 4.1.n) de la LCSP excluye de su ámbito de aplicación:

"Los negocios jurídicos en cuya virtud se encargue a una entidad que, conforme a lo señalado en el artículo 24.6, tenga atribuida la condición de medio propio y servicio técnico del mismo, la realización de una determinada prestación”.

Sin embargo, el precepto somete a continuación al régimen de la Ley los contratos que pueda celebrar el medio propio con terceros:

“...No obstante, los contratos que deban celebrarse por las entidades que tengan la consideración de medio propio y servicio técnico para la realización de las prestaciones objeto del encargo quedarán sometidos a esta Ley, en los términos que sean procedentes de acuerdo con la naturaleza de la entidad que los celebre y el tipo y cuantía de los mismos, y, en todo caso, cuando se trate de contratos de obras, servicios o suministros cuyas cuantías superen los umbrales establecidos en la Sección 2. ${ }^{a}$ del Capítulo II de este Título Preliminar, las entidades de derecho privado deberán observar para su preparación y adjudicación las reglas establecidas en los artículos 121.1 y 174 ".

De acuerdo con el apartado 6 del artículo 24 de la Ley 30/2007, los entes, organismos y entidades del sector público podrán ser considerados medios propios y servicios técnicos de aquellos poderes adjudicadores para los que realicen la parte esencial de su actividad cuando éstos ostenten sobre los mismos un control análogo al que pueden ejercer sobre sus propios servicios. Si se trata de sociedades, además, la totalidad de su capital tendrá que ser de titularidad pública. 
En todo caso, la LCSP presume que los poderes adjudicadores ostentan sobre un ente, organismo o entidad un control análogo al que tienen sobre sus propios servicios si pueden conferirles encomiendas de gestión que sean de ejecución obligatoria para ellos de acuerdo con instrucciones fijadas unilateralmente por el encomendante y cuya retribución se fije por referencia a tarifas aprobadas por la entidad pública de la que dependan (segundo párrafo del apartado 6 del artículo 24).

La condición de medio propio y servicio técnico de las entidades que cumplan los criterios mencionados en el apartado 6 del artículo 24 deberá reconocerse expresamente por la norma que las cree o por sus estatutos, que deberán determinar las entidades respecto de las cuales tienen esta condición y precisar el régimen de las encomiendas que se les puedan conferir o las condiciones en que podrán adjudicárseles contratos, y determinará para ellas la imposibilidad de participar en licitaciones públicas convocadas por los poderes adjudicadores de los que sean medios propios, sin perjuicio de que, cuando no concurra ningún licitador, pueda encargárseles la ejecución de la prestación objeto de las mimas.

Estos preceptos de la nueva Ley de Contratos tratan de incorporar la importante doctrina elaborada por el Tribunal de Justicia de las Comunidades Europeas en relación con los denominados contratos "in house providing", por medio de los cuales se encarga la prestación de una obra o servicio a un ente instrumental sin que se aplique la legislación contractual ${ }^{24}$.

Es la falta de autonomía de decisión de uno de los entes respecto del otro la razón que impide la existencia de un contrato entre ellos ${ }^{25}$.

Los contratos "in house" son la excepción a la regla general de sometimiento a los procedimientos públicos de todo tipo de contratos celebrados por los poderes adjudicadores. Como declaró el TJCE en la sentencia de 18 de noviembre de 1999, Teckal (C-107/98, Rec. p. I-8121, apartados 49 a 51), para la aplicación de la normativa comunitaria sobre contratación pública, basta, en principio, con que el contrato haya sido celebrado entre, por una parte, un ente territorial y, por otra, una persona jurídicamente distinta de éste, "sólo puede ser de otra manera en el supuesto de que, a la vez, el ente territorial ejerza sobre la persona de que se trate un control análogo al que ejerce sobre sus propios servicios y esta persona realice la parte

${ }^{24}$ Véase al respecto Fuertes López, M. y Sosa Wagner, F., “¿Pueden los contratos quedar en casa? (La polémica europea sobre la contratación in house)”, Diario La Ley n. ${ }^{\circ}$ 6715, Año XXVIII, 17 may. 2007, Ref. ${ }^{a}$ D-118, pp. 4 y ss.

${ }^{25}$ Véase Amoedo Souto, "El nuevo régimen jurídico de la encomienda de ejecución y su repercusión sobre la configuración de los entes instrumentales de las Administraciones Públicas”, RAP 170 (2006), pp. 264 y ss. 
esencial de su actividad con el ente o los entes a que pertenece" (la cursiva es añadida).

No se aplicará pues lo dispuesto en el Derecho comunitario y nacional de la contratación pública en el supuesto de que, cumulativamente, la autoridad pública concedente ejerza sobre la entidad concesionaria un control análogo al que ejerce sobre sus propios servicios y la entidad realice la parte esencial de su actividad junto con la autoridad a que pertenece (sentencia del TJCE de 13 de octubre de 2005, asunto C-458/03, Parking Brixen GMBH).

El Tribunal de Justicia ha confirmado la aplicabilidad de las mismas consideraciones a las Directivas 92/50, relativa a los contratos públicos de servicios, y 93/37/CEE del Consejo, de 14 de junio de 1993, sobre coordinación de los procedimientos de adjudicación de los contratos públicos de obras — antecedentes ambas de la Directiva 2004/18/CE, que las ha derogado- (véanse, respectivamente, las sentencias de 11 de enero de 2005, Stadt Halle y RPL Lochau, C-26/03, Rec. p. I-1, apartados 48, 49 y 52, y de 13 de enero de 2005, Comisión/Espańa, C-84/03, Rec. p. I-139, apartado 39). El TJCE parte de la premisa de que la aplicación de las directivas sobre contratos públicos depende de la existencia de un contrato celebrado entre dos personas distintas (véase la sentencia Teckal, antes citada, apartados 46 y 49$)$.

Más allá de las directivas de contratos, debe señalarse que dichas consideraciones pueden trasponerse a las disposiciones del Tratado y principios relativos a las concesiones de servicios públicos excluidas del ámbito de aplicación de las directivas sobre contratación pública. En efecto, en el ámbito de la contratación pública y de las concesiones de servicios públicos, el principio de igualdad de trato y sus expresiones específicas, que son la prohibición de discriminación por razón de nacionalidad y los artículos 43 CE y 49 $\mathrm{CE}$, son aplicables en el supuesto de que una autoridad pública encomiende la prestación de actividades económicas a un tercero. En cambio, no procederá aplicar las normas comunitarias en materia de contratación pública o de concesiones de servicios públicos en caso de que una autoridad pública realice las tareas de interés público que le corresponden con sus propios medios administrativos, técnicos y de cualquier otro tipo, sin recurrir a entidades externas (véase en este sentido la sentencia Stadt Halle y RPL Lochau, antes citada, apartado 48).

Dado que se trata de una excepción a las normas generales del Derecho comunitario, los dos requisitos exigidos por el Tribunal (que, a la vez, el ente territorial ejerza sobre la persona de que se trate un control análogo al que ejerce sobre sus propios servicios y esta persona realice la parte esencial de su actividad con el ente o los entes a que pertenece) deben ser objeto de una 
interpretación estricta, y la carga de la prueba de que existen realmente las circunstancias excepcionales que justifican la excepción a dichas normas incumbe a quien quiera beneficiarse de ella (sentencia Stadt Halle y RPL Lochau, antes citada, apartado 46).

Pues bien, en muchos casos Administraciones públicas españolas aplican indebidamente esta doctrina y consideran medio propio de la Administración a entidades que no reúnen los requisitos para ello ${ }^{26}$. La cuestión es muy polémica y está sujeta a controversias que en algunos supuestos, como el de TRAGSA, han dado lugar a diversos pronunciamientos judiciales.

En efecto, el legislador estatal y autonómico ${ }^{27}$ ha venido a calificar diversas sociedades como medios propios de la Administración. Se trata de socie-

${ }^{26}$ Comentan la incorporación en la LCSP de la doctrina del TJCE sobre los contratos in house GIMENO FELIÚ, J.M., "El ámbito objetivo de aplicación de la LCSP" y BERNAL BLAY, M.A., "La problemática relativa a los contratos excluidos de la aplicación de la Ley: los encargos in house, con especial referencia al ámbito local", en AAVV (coordinación MORENO MOLINA, J.A.), La nueva Ley de Contratos del Sector Público y su aplicación por las entidades locales, CEMCI, Granada, 2008, pp. 119 y ss. y 167 y ss., respectivamente.

${ }_{27}$ Por ejemplo, la empresa "Gestió d'Infraestructures, S.A." (en adelante, GISA) fue constituida por acuerdo del Gobierno de la Generalitat de Catalunya adoptado el 3 de julio de 1990. El capital de GISA fue suscrito íntegramente por la Generalitat. El Parlamento de Catalunya acordó la constitución de la Sociedad según la Disposición Adicional número 29 de la Ley 9/1990 del 16 de mayo. El 3 de julio de 1990, el Gobierno de la Generalitat aprobó el Decreto Constitutivo de GISA. De acuerdo con su objeto social, GISA actúa en nombre y por cuenta propia o en nombre propio y por cuenta de la Generalitat de Catalunya con la finalidad de proyectar, construir, conservar, explotar y promocionar las obras públicas de todo tipo y los servicios que puedan instalarse o desarrollarse en relación con las infraestructuras que promueve o en las que participa la Generalitat (disposición adicional 25 de la Ley 14/1996, de 29 de julio, de Presupuestos de la Generalitat de Catalunya para el año 1996). Tras la aprobación por el Parlamento de Catalunya de la Ley 31/2002, de 30 de diciembre, de Medidas Fiscales y Administrativas publicada en el Diari Oficial de la Generalitat de Catalunya núm. 3791, de 31 de diciembre, y la corrección de errores en la misma Ley publicada en el Diari Oficial de la Generalitat de Catalunya núm. 3805, de 22 de enero de 2003, se decidió modificar el segundo artículo de los Estatutos Sociales relativo al objeto social de la Compañía y darle el siguiente contenido:

"Proyectar construir, conservar, explotar y promocionar todo tipo de infraestructuras y edificaciones que la Generalitat promueva o en las que participe y los servicios que se puedan instalar o desarrollar. Proyectar y construir todo tipo de infraestructuras y edificaciones de terceros con los que la Generalitat haya acordado su construcción. Estas actividades pueden ser llevadas a cabo por Gestió d'Infraestructures, SA, que actúa por encargo del Gobierno, en nombre propio y por cuenta propia, o en nombre propio y por cuenta de la Generalitat o de terceras personas, según los términos de los encargos y los mandatos de actuación. Estas actividades se pueden llevar a cabo total o parcialmente por medio de la participación, que está sujeta siempre al Estatuto de la Empresa Pública Catalana, a la Ley 11/1981, de 7 de diciembre, de Patrimonio de la Generalitat, y al Reglamento que la desarrolla, y a cualquier otra disposición que sea aplicable por el carácter de empresa pública de la sociedad, en sociedades de objeto idéntico o análogo”. 
dades mercantiles de capital público, que actúan por cuenta de la Administración, y que por ello reciben la condición de medio propio ${ }^{28}$.

Éste es el caso del artículo 88 de la Ley 66/1997, de 30 de diciembre, de medidas fiscales, administrativas y del orden social, que otorga a la empresa pública TRAGSA la calificación de medio propio de la Administración estatal y, en su caso, autonómica (aunque no la local como precisa el informe 46/98, de 17 de marzo, de la Junta Consultiva); la disposición adicional segunda de la Ley 53/1999, conforme al cual "la Sociedad Estatal de Gestión Inmobiliaria de Patrimonio, S. A. (SEGIPSA), cuyo capital social deberá ser de titularidad pública, tendrá la consideración de medio propio instrumental y servicio técnico de la Administración, yestará obligada a realizar los trabajos que le encomiende la Administración General del Estado y sus organismos y entidades de Derecho público y las Entidades gestoras y Servicios comunes de la Seguridad Social"; y el artículo 67 de la Ley 24/2001, de 27 de diciembre, respecto de la Sociedad Estatal para las Enseńanzas Aeronáuticas Civiles (SENASA).

En particular, el artículo 88.4 de la Ley 66/1997, de 30 de diciembre, dispone que "TRAGSA, como medio propio instrumental y servicio técnico de la Administración, está obligada a realizar (...) los trabajos que le encomienden la Administración General del Estado, las Comunidades Autónomas y los organismos públicos de ellas dependientes, en las materias que constituyen el objeto social de la empresa (...)"; y, en virtud de lo prevenido en el apartado cinco de dicha disposición "ni TRAGSA ni sus filiales podrán participar en los procedimientos para la adjudicación de contratos convocados por las Administraciones Públicas de las que sea medio propio".

Para la Administración del Estado, TRAGSA, aunque es una entidad formalmente distinta (goza de personalidad jurídica propia), no es autónoma desde un punto de vista decisorio, y no existe contrato entre ambas entidades sino una actuación de TRAGSA obligatoria y derivada de una orden de la Administración. TRAGSA y la Administración no celebrarían contrato alguno, ya que la segunda ordena a la primera realizar ciertos trabajos y la primera está obligada a ejecutar dicha orden, y en la ejecución de la orden la Administración goza de control sobre TRAGSA. Conforme al artículo 1261 del Código Civil, "no hay contrato sino cuando concurren los requisitos siguientes: $1 .{ }^{\circ}$. Consentimiento de los contratantes...”. Y a tenor del artículo 1262 del mismo cuerpo legal "el consentimiento se manifiesta por el concurso de la oferta y de la aceptación sobre la cosa y causa que han de consti-

${ }^{28}$ Véase GonzÁlez García, J.V., "Medios propios de la Administración, colaboración interadministrativa y sometimiento a la normativa comunitaria de contratación", Revista de Administración Pública, núm. 173, año 2007, pp. 217-237. 
tuir el contrato". Pues bien, de acuerdo con ello TRAGSA ni ofrecería, ni aceptaría, ni, por tanto, consentiría el establecimiento de una determinada relación jurídica sino que ésta surge de la orden unilateral de la Administración autonómica.

Tal y como se indica literalmente en el apartado 2 del artículo 3 del Real Decreto 371/1999, de 5 de marzo, "TRAGSA y sus filiales están obligadas a realizar los trabajos y actividades que le sean encomendados por la Administración... como su medio propio instrumental y servicio técnico, en las materias que constituyen su objeto social", a lo que añade el apartado 6 del mismo artículo que "las relaciones de TRAGSA y sus filiales con las Administraciones Públicas en su condición de medio propio y servicio técnico tienen naturaleza instrumental y no contractual, por lo que a todos los efectos son de carácter interno, dependiente y subordinado". Es más, como establece el artículo 4.7 del propio Real Decreto, "las nuevas tarifas, la modificación de las existentes y los procedimientos, mecanismos y fórmulas de revisión, serán aprobadas por cada una de las Administraciones Públicas de las que TRAGSA y sus filiales sean medio propio y servicio técnico", lo cual no se compadece con una relación contractual.

Tradicionalmente nuestro ordenamiento jurídico administrativo ha mantenido una posición restrictiva en cuanto a la posibilidad de que la Administración ejecute directamente obras. En este sentido, el artículo 60 de la Ley de Contratos del Estado señalaba que "sólo podrán ser ejecutadas directamente por la Administración las obras en que concurra alguna de estas circunstancias...”. Sin embargo, este carácter de excepción resultó seriamente matizado por la generalidad de los supuestos que contempla el artículo 152 del TRLCAP.

El Tribunal Supremo ha considerado los supuestos de ejecución de obras por la Administración a través del encargo a una sociedad de naturaleza jurídico-privada como ajustados a la Constitución y a las normas sobre la competencia, señalando así en su sentencia de 18 de diciembre de 2003 (Sala 3. ${ }^{a}$, Sección 4. ${ }^{a}$, recurso 1120/2001) que:

"Pero además debemos entender que la Sentencia no vulnera las normas sobre contratación, ya que es preciso atenerse a la normativa del artículo 153 de la Ley de Contratos de las Administraciones públicas que regula la ejecución de obras por medios propios, como la propia Sentencia declara, no existiendo razón alguna para que este precepto se entienda que es contrario a la Constitución. De ello se deduce que debemos compartir asimismo el juicio de la resolución recurrida en el sentido de que no procede plantear cuestión de inconstitucionalidad. En cuanto a las supuestas vulneraciones de la Constitución el precepto decisivo invocado, esto es, el artículo 128, debe interpretarse rectamente entendiendo que, no sólo admite que los entes públicos sean titula- 
res de actividades económicas, sino también que realicen obras por medios propios como una variedad o manifestación de la iniciativa económica. En cuanto a la vulneración de las normas sobre la competencia debe estarse a la declaración de la Sentencia impugnada, que no ha sido debidamente contradicha. Por último respecto a la vulneración de las Directivas comunitarias la representación de TRAGSA mantiene, y nada se ha alegado en contrario, que la misma Comisión de la Comunidad Europea en cuyo conocimiento se puso no formuló reparo alguno al sistema de contratación realizando obras por medios propios de las Administraciones públicas”.

Pues bien, en la sentencia del TJCE de 19 de abril de 2007, asunto C-295/05, el alto Tribunal europeo resuelve las cuestiones prejudiciales planteadas por el Tribunal Supremo español en relación con la atribución ex lege a TRAGSA de un régimen jurídico que le permite realizar obras públicas sin sometimiento al régimen general de contratación administrativa mediante concurso, sin concurrir circunstancias especiales de urgencia o interés público, tanto por debajo como superando el umbral económico contemplado por las directivas europeas a este respecto. Se planteaba pues en el asunto la compatibilidad del régimen jurídico de TRAGSA con lo establecido en las directivas de contratación pública.

El asunto tenía su origen en una petición de decisión prejudicial planteada en el marco de un litigio entre la Asociación Nacional de Empresas Forestales y la Administración del Estado relativo a una denuncia presentada contra el régimen jurídico de que disfruta TRAGSA. La petición de decisión prejudicial versaba sobre la cuestión de si, con arreglo al artículo 86 CE, apartado 1, un Estado miembro puede atribuir a una empresa pública un régimen jurídico que le permite llevar a cabo operaciones sin estar sujeta a las Directivas 92/50/CEE del Consejo, de 18 de junio de 1992, sobre coordinación de los procedimientos de adjudicación de los contratos públicos de servicios, 93/36/CEE del Consejo, de 14 de junio de 1993, sobre coordinación de los procedimientos de adjudicación de contratos públicos de suministro, y 93/37/CEE del Consejo, de 14 de junio de 1993, sobre coordinación de los procedimientos de adjudicación de los contratos públicos de obras, y si estas directivas se oponen a tal régimen.

Para el TJCE, TRAGSA está obligada a realizar los trabajos que le encomienden, en las materias que constituyen su objeto social, la Administración General del Estado, las Comunidades Autónomas y los organismos públicos dependientes de ellas, y no tiene la posibilidad de fijar libremente la tarifa de sus intervenciones. Por ello, las relaciones de TRAGSA con estos entes públicos no tienen naturaleza contractual, sino que son, a todos los efectos, de carácter interno, dependiente y subordinado, en la medida en que esta sociedad constituye un medio propio instrumental y un servicio 
técnico de tales entes. Observa pues el Tribunal que, si Tragsa no goza de libertad alguna ni con respecto al curso que debe dar a un encargo formulado por las autoridades competentes ni en cuanto a la tarifa aplicable a sus prestaciones, afirmación que incumbe verificar al órgano jurisdiccional nacional, no se cumple el requisito de aplicabilidad de las Directivas examinadas relativo a la existencia de un contrato.

En su sentencia, el Tribunal examina si en el caso de TRAGSA se cumplen los dos requisitos exigidos por la jurisprudencia comunitaria:

“(...) En lo que se refiere al primer requisito, relativo al control de la autoridad pública, de la jurisprudencia del Tribunal de Justicia resulta que el hecho de que el poder adjudicador posea, por sí solo o junto con otros poderes públicos, la totalidad del capital de una sociedad adjudicataria tiende a indicar, en principio, que este poder adjudicador ejerce sobre dicha sociedad un control análogo al que ejerce sobre sus propios servicios (sentencia Carbotermo y Consorzio Alisei, antes citada, apartado 37). En el asunto principal resulta de los autos, y a reserva de comprobación por el órgano jurisdiccional remitente, que el $99 \%$ del capital social de Tragsa pertenece al Estado español, directamente y a través de una sociedad holding y de un fondo de garantía, y que cuatro Comunidades Autónomas, titulares cada una de una acción, poseen el $1 \%$ de dicho capital. A este respecto, no cabe acoger la tesis de que sólo se cumple este requisito para los trabajos realizados por encargo del Estado español, quedando excluidos los que hayan sido encargados por las Comunidades Autónomas, con respecto a las cuales Tragsa debe ser considerada un tercero. En efecto, del artículo 88, apartado 4, de la Ley 66/1997 y de los artículos 3, apartados 2 a 6, y 4, apartados 1 y 7, del Real Decreto 371/1999 parece derivarse que Tragsa está obligada a realizar los trabajos que le encomienden los poderes públicos, incluidas las Comunidades Autónomas. De esta normativa nacional también parece deducirse que, en el marco de sus actividades con las Comunidades Autónomas como medio propio instrumental y servicio técnico de éstas, y al igual que ocurre en sus relaciones con el Estado espańol, Tragsa no tiene la posibilidad de fijar libremente la tarifa de sus intervenciones y sus relaciones con dichas Comunidades no tienen naturaleza contractual. Por consiguiente, parece que Tragsa no puede tener la consideración de tercero con respecto a las Comunidades Autónomas que poseen una parte de su capital.

(...) En cuanto al segundo requisito, conforme al cual Tragsa debe realizar lo esencial de su actividad con el ente o entes públicos a los que pertenece, de la jurisprudencia resulta que, cuando son varios los entes territoriales que controlan una empresa, este requisito puede considerarse satisfecho si dicha empresa realiza lo esencial de su actividad, no necesariamente con uno u otro de estos entes territoriales, sino con dichos entes territoriales considerados en conjunto (sentencia Carbotermo y Consorzio Alisei, antes citada, apartado 70). En el asunto principal, como resulta de los autos, Tragsa realiza por término medio más del $55 \%$ de su actividad con las Comunidades Autónomas y alrededor de un $35 \%$ 
con el Estado. De lo anterior resulta que esta sociedad realiza lo esencial de su actividad con los entes territoriales y los organismos públicos que la controlan. En estas circunstancias, procede considerar, a reserva de comprobación por el órgano jurisdiccional remitente, que en el caso de autos se cumplen los dos requisitos exigidos por la jurisprudencia citada en el apartado 55 de la presente sentencia”.

En definitiva, la sentencia del TJCE considera que TRAGSA es una empresa pública que actúa como medio propio instrumental y servicio técnico de varias autoridades públicas (principalmente Estado y Comunidades Autónomas), por lo que puede realizar obras públicas por encargo sin sometimiento al régimen general de contratación administrativa.

El discutible fallo del Tribunal llama poderosamente la atención por la interpretación que realiza de los requisitos sentados en su jurisprudencia sobre los denominados contratos "in house providing", interpretación que se aparta además de las bien fundamentadas Conclusiones presentadas el 28 de septiembre de 2006 por el Abogado General Sr. GeElHed.

En efecto, en sus Conclusiones en el asunto C-295/05 el Abogado llegaba a la evidente consideración de que TRAGSA, operando bajo un estatuto legal como el vigente actualmente, no puede ser considerada como "medio propio" de las Comunidades Autónomas porque éstas no pueden controlar las decisiones estratégicas y otras decisiones importantes de esta persona jurídica.

Ya en su sentencia de 8 de mayo de 2003, en el asunto España/Comisión, el Tribunal de Justicia de las Comunidades Europeas concluyó que un organismo como TRAGSA que, pese a su autonomía financiera y contable, está plenamente sujeto al control del Estado español debe considerarse un servicio propio de la Administración española, en el sentido del artículo 3, apartado 5, párrafo primero, del Reglamento n. ${ }^{\circ} 154 / 75$. Ahora bien, esta apreciación del Tribunal de Justicia se refería a las actividades que TRAGSA realizó por encargo del Estado español para el establecimiento de un registro oleícola.

De acuerdo con la sentencia del TJCE de 19 de abril de 2007, la Disposición adicional 30 de la LCSP aprovecha para declarar, en su apartado 2, que

“TRAGSA y sus filiales integradas en el grupo definido en el apartado anterior tienen la consideración de medios propios instrumentales y servicios técnicos de la Administración General del Estado, las Comunidades Autónomas y los poderes adjudicadores dependientes de ellas, estando obligadas a realizar, con carácter exclusivo, los trabajos que éstos les encomienden en las materias señaladas en los apartados 4 y 5 , dando una especial prioridad a aquéllos que sean ur- 
gentes o que se ordenen como consecuencia de las situaciones de emergencia que se declaren. De acuerdo con esta obligación, los bienes y efectivos de TRAGSA y sus filiales podrán incluirse en los planes y dispositivos de protección civil y de emergencias.

Las relaciones de las sociedades del grupo TRAGSA con los poderes adjudicadores de los que son medios propios instrumentales y servicios técnicos tienen naturaleza instrumental y no contractual, articulándose a través de encomiendas de gestión de las previstas en el artículo 24.6 de esta Ley, por lo que, a todos los efectos, son de carácter interno, dependiente y subordinado".

El amplio contenido de la disposición, con la muy generosa consideración de medio propio de TRAGSA y sus filiales, entiendo resulta contrario a la doctrina general del Tribunal europeo de Justicia sobre los contratos "in house", anteriormente comentada ${ }^{29}$.

\section{LA EXCLUSIÓN DE LOS CONTRATOS EN EL SECTOR DE LA DEFENSA. LA FALTA DE APLICACIÓN DE LOS PRINCIPIOS DE CONCURRENCIA Y TRANSPARENCIA EN EL ÁMBITO DE LOS CONTRATOS PÚBLICOS DE DEFENSA LA NECESIDAD DE GARANTIZAR EL RESPETO DE LOS PRINCIPIOS DE LA CONTRATACIÓN PÚBLICA CON ALGUNAS ESPECIALIDADES}

Los gastos de defensa constituyen una parte importante de los gastos públicos, aproximadamente 160.000 millones de euros para los Estados miembros de la Unión; una quinta parte de esa cantidad se dedica a las compras de equipos militares (adquisiciones e investigación y desarrollo) ${ }^{30}$. Estas cifras adquieren especial relevancia si se considera la importancia de la industria militar para el desarrollo de las altas tecnologías, las cuales pueden después ser transferidas para usos civiles ${ }^{31}$.

${ }^{29}$ Critican el paso "en falso" del Tribunal y lo contradictorio de algunos de sus últimos pronunciamientos sobre los encargos in house, BERNAL BLAY, M.A., "La problemática relativa a los contratos excluidos...”, op. cit., pág. 178, y Gimeno Feliú, J.M., "El ámbito objetivo de aplicación...", op. cit., pp. 199 y ss.

30 Véase la Comunicación de la Comisión Europea titulada "Hacia una política de la UE en materia de equipo de defensa", adoptada el 11 de marzo de 2003, $\operatorname{COM(2003)~} 113$ final.

31 Arrowsmith, S. y Fernández Martín, J.M., "Developments in Public Procurement in 1992”, European Law Review, 1993, p. 344. Véase también Canales Gil, A. y Elices Huecas, A., "La contratación por el Ministerio de Defensa de armamento y material: las compensaciones económicas, industriales y tecnológicas", y Esguevillas Ramos, L., "La industria española de la Defensa y el gasto militar. Perspectivas futuras", en Gasto militar y crecimiento económico. 
Pero la importancia económica, política y social de este sector de las compras públicas contrasta con la falta de garantía de la no discriminación, la transparencia y la igualdad de trato entre las empresas. Como ha puesto de manifiesto la Comisión Europea, la situación observada en los contratos públicos de defensa muestra que varios obstáculos limitan las posibilidades de acceso de las industrias europeas a los contratos de los Estados miembros y, en consecuencia, también limitan sus oportunidades de crecimiento ${ }^{32}$. En la actualidad, los contratos públicos de defensa se caracterizan por una compartimentación a nivel nacional, por especificidades que los diferencian de los demás contratos públicos y por un marco jurídico cuya aplicación es compleja.

En efecto, si bien el total de los gastos militares de los Estados miembros es considerable, existe una gran fragmentación a nivel de los contratos de tipo nacional, lo que plantea en la actualidad un grave problema para todos los Estados miembros con industrias de defensa. Tras las reducciones de los presupuestos y la reestructuración de las fuerzas armadas, el tamaño de los mercados nacionales —incluidos los de los grandes Estados- ya no es suficiente para alcanzar volúmenes de producción que permitan amortiguar los elevados costes de investigación y desarrollo de los sistemas de armas. Esta situación, así como la fragmentación de los esfuerzos de investigación y desarrollo en Europa, implica un coste excesivo para los contribuyentes y perjudica a la competitividad de la industria europea de defensa y a su capacidad para responder a las necesidades de capacidad de la PESD ${ }^{33}$.

Las especificidades de los contratos de defensa se derivan de la propia naturaleza de los bienes militares y los servicios correspondientes. No son solamente de carácter económico y tecnológico, sino que dependen también de la política de seguridad y defensa de cada uno de los Estados miembros.

A raíz de las privatizaciones y de los esfuerzos de máximo aprovechamiento de las políticas de adquisición de estos últimos ańos, el papel de los Estados se ha reducido, si bien sigue siendo aún predominante. Como clientes exclusivos, los Estados determinan la demanda de los productos en función de unas necesidades militares vinculadas a sus objetivos estratégicos y definen así el tamaño de los contratos. Los imperativos de defensa suponen que las fuentes de suministro estén garantizadas durante toda la vida de los

Aproximación al caso español, Cuadernos de Estrategia del Centro Superior de Estudios de la Defensa Nacional, n. ${ }^{\circ}$ 64, Ministerio de Defensa, Madrid, 1994, pp. 101 y ss. y 77 y ss., respectivamente.

32 Libro verde: "Los contratos públicos de defensa" (COM/2004/0608 final), apartado I.

33 Libro verde: "Los contratos públicos de defensa", cit., apartado I.1. 
programas de armamento, desde la concepción hasta la retirada del servicio del equipamiento, en tiempos de paz y en tiempos de guerra ${ }^{34}$.

En cuanto a la regulación jurídica de los contratos en el sector de la defensa, la norma de cabecera en la materia es el artículo 296 del Tratado de la Comunidad Europea, que establece una exención de la aplicación de las normas del Tratado en el sector de la defensa nacional, al disponer que "todo Estado miembro podrá adoptar las medidas que estime necesarias para la protección de los intereses esenciales de su seguridad y que se refieran a la producción o al comercio de armas, municiones y material de guerra; estas medidas no deberán alterar las condiciones de competencia en el mercado común respecto de los productos que no estén destinados a fines específicamente militares".

Esta norma fue desarrollada por la Directiva 77/62/CEE, sobre coordinación de los procedimientos de adjudicación de contratos públicos de suministro, cuyo artículo 2 bis $^{35}$ seńalaba que "sin perjuicio de lo dispuesto en los artículos 2 y 3 y en el apartado 1 del artículo 5, la presente Directiva se aplicará a todos los productos, en el sentido que se recoge en la letra a) del artículo 1, incluidos los comprendidos en contratos adjudicados por los poderes adjudicadores en el sector de la defensa, con excepción de los productos a los que se aplica la letra b) del apartado 1 del artículo 223 del Tratado" ${ }^{36}$.

Como señalaba la Comisión en su "Guía sobre las normas comunitarias para la apertura de la contratación pública" ${ }^{37}$, no están sujetos a las reglas comunitarias aquellos contratos públicos en el ámbito de la defensa que conciernan a productos destinados a usos exclusivamente militares, por ejemplo, armas, municiones y material de guerra, los cuales están cubiertos por el artículo 296 del Tratado de la Comunidad Europea ${ }^{38}$.

Sin embargo, la determinación de si un contrato se refiere o no a productos "que se destinan a fines específicamente militares" se presenta ciertamente complicada. Desde luego, es una cuestión de Derecho comunitario y exige un estudio producto por producto, y no por categorías enteras.

${ }^{34}$ Libro verde: "Los contratos públicos de defensa", cit., apartado I.2.

35 Introducido por el artículo 4 de la Directiva 88/295/CEE, de 22 de marzo de 1988.

36 Esta disposición fue recogida en el artículo 3 de la Directiva 93/36/CEE, de 14 de junio de 1993, sobre coordinación de los procedimientos de adjudicación de contratos públicos de suministro.

${ }^{37}$ DOCE n. ${ }^{\circ}$ C 358, de 31 de diciembre de 1987, p. 19.

38 Una lista de esos productos fue establecida por una Decisión del Consejo de 15 de abril de 1958. Desde entonces, esta lista no ha sido modificada. Por cierto, la lista nunca ha sido publicada oficialmente (véase WAINwright, R., "Rapport communautaire", en FIDE, 14 Congreso, Centro de Publicaciones del Ministerio de Justicia, Madrid, 1990, p. 19, nota 16). 
El artículo 2.2.c) de la Directiva 77/62/CEE ${ }^{39}$ introdujo a su vez otra exención para "los suministros que se declaren secretos o cuya ejecución deba ir acompañada de especiales medidas de seguridad, con arreglo a las disposiciones legales, reglamentarias o administrativas vigentes en el Estado miembro de que se trate o cuando así lo requiera la protección de los intereses esenciales de la seguridad de dicho Estado miembro" ${ }^{40}$.

Esta última exención debe ser interpretada como una expresión de la "excepción de seguridad pública" prevista en el artículo 36 del Tratado de la Comunidad Europea.

Por otra parte, también se prevé una exención para las compras militares en el ámbito del Acuerdo GATT. En concreto, el artículo VIII, apartado primero, del Acuerdo sobre Compras del Sector Público ${ }^{41}$, señala que ninguna disposición del Acuerdo se interpretará "en el sentido de que impida a una Parte adoptar las medidas o abstenerse de revelar las informaciones, que considere necesario para proteger sus intereses esenciales en materia de seguridad en relación con la compra de armas, municiones o material de guerra, o cualquier otra compra indispensable para la seguridad nacional o para fines de defensa nacional".

La vigente Directiva 2004/18/CE reitera en su artículo 10 que la normativa comunitaria en materia de contratos públicos se aplicará a los contratos públicos adjudicados por los poderes adjudicadores en el sector de la defensa, a reserva del artículo $296 \mathrm{CE}$ del Tratado. Como hemos visto, la posibilidad de excepción prevista en el artículo 296 del Tratado CE no se aplica ni a los bienes civiles ni a los no destinados a fines específicamente militares, incluso si los adquieren los Ministerios de Defensa nacionales.

La jurisprudencia del TJCE ha delimitado las condiciones de utilización de esta excepción de manera restrictiva, indicando en su sentencia Johnston, asunto 222/84 y en su sentencia Comisión contra España, asunto C-414/97 que:

- Su utilización no constituye una reserva general y automática sino que debe justificarse individualmente. Los Estados pueden de este modo otorgar carácter secreto a la información que pudiera poner en peligro su seguridad, así como alegar una exención a las normas

39 Añadido por el artículo 3 de la Directiva 88/295/CEE. Esta disposición ha sido recogida en el artículo 2.1.b) de la Directiva 93/36/CEE, de 14 de junio de 1993.

${ }^{40}$ Una cláusula similar contiene el apartado b) del artículo 4 de la Directiva 93/37/CEE, sobre coordinación de los procedimientos de adjudicación de los contratos públicos de obras.

${ }^{41}$ El Acuerdo fue publicado en el DOCE n. ${ }^{\circ} \mathrm{L} 71 / 44$, de 17 de marzo de 1980. 
del mercado interior en materia de comercio de armamento, y han de evaluar, para cada contrato, si está cubierto o no por la excepción.

- La utilización de las medidas nacionales de excepción por los Estados sólo se justifica si son necesarias para realizar el objetivo de protección de los intereses esenciales de seguridad alegados.

- La carga de la prueba incumbe al Estado miembro que desee recurrir a las mismas.

- Esta prueba deberá aportarse, si fuere necesario, a los jueces nacionales o bien, cuando proceda, al Tribunal de Justicia, al que podría recurrir la Comisión en el ejercicio de su función de guardiana del Tratado.

Por regla general, los Estados miembros pueden por tanto no aplicar las normas del Tratado y las directivas comunitarias, pero sólo con condiciones muy concretas. Sin embargo, surgen varias dificultades al aplicar la excepción.

En efecto, a falta de una interpretación precisa de estas disposiciones, se ha venido recurriendo casi sistemáticamente a esta excepción en lo que atañe a los contratos públicos. A pesar de las aclaraciones del Tribunal, el escaso número de publicaciones en el Diario Oficial de la Unión Europea deja entrever que algunos Estados miembros consideran que pueden recurrir a la excepción de manera automática ${ }^{42}$.

Por otra parte, dado que ni el Derecho comunitario ni la jurisprudencia del Tribunal han definido el concepto de interés esencial de seguridad, los Estados se reservan en la práctica un amplio margen de apreciación para determinar los contratos que pueden afectar a tal interés.

Para circunscribir el ámbito de aplicación del artículo 296 CE, la lista de $1958^{43}$ no constituye una base de referencia conveniente en la medida en que nunca se ha publicado oficialmente, ni se ha revisado con posterioridad.

Por consiguiente, se observa que los contratos de defensa se rigen todavía en gran medida por las legislaciones meramente nacionales. La contratación pública comunitaria en el campo de la defensa se presenta como un sector escasamente regulado, basado en excepciones a las normas aplicables al resto de los contratos, y que, sin duda, está necesitado de una decidida

${ }^{42}$ Libro verde: "Los contratos públicos de defensa" (COM/2004/0608 final), apartado I.3.

${ }^{43}$ La lista ha pretendido ser ampliada por la que se ha publicado en el Anexo II de la Directiva 80/767/CEE, de 22 de julio de 1980, que modifica la Directiva 77/62/CEE, sobre los contratos de suministro (DOCE n. $^{\circ} 215$, de 18 de agosto de 1980). Como ha señalado MiranDA González, J., una unión de ambas listas podría considerarse como el punto de referencia para determinar los materiales excluidos o no del cumplimiento de las Directivas comunitarias en el ámbito de la defensa ("La contratación de las Fuerzas Armadas y las Directivas de contratos públicos en la Comunidad Económica Europea”, Noticias CEE, núm. 21 (1986), p. 91). 
acción comunitaria ${ }^{44}$, que, eso sí, tenga en cuenta las peculiaridades y especialidades de la contratación militar ${ }^{45}$.

El marco reglamentario comunitario debería completarse con un nuevo instrumento legislativo específico de los contratos de defensa (bienes, servicios y obras), que coordine las formas de adjudicación de estos contratos. En este sentido, con fecha 5 de diciembre de 2007, la Comisión presentó la Propuesta de Directiva del Parlamento Europeo y del Consejo sobre coordinación de los procedimientos de adjudicación de determinados contratos públicos de obras, de suministro y de servicios en los ámbitos de la defensa y la seguridad [COM(2007) 766 final]. Su planteamiento es similar al efectuado en 1990 para tener en cuenta las particularidades de los contratos en los sectores del agua, la energía y los transportes, mediante una Directiva específica (la 93/38, modificada mediante la Directiva 2004/17/CE de 31 de marzo de 2004). Esta directiva pretende pues establecer un marco específico de normas aplicables a los contratos que entran en el ámbito de aplicación ratione materiae del artículo 296 CE. Se aplicaría a los contratos de defensa que entran actualmente en el ámbito de aplicación de las directivas existentes, pero permitiría disponer de normas que corresponden en mayor medida a sus especificidades.

Los objetivos principales de la directiva sobre contratos en el sector de la defensa serían tres:

1) Una mayor seguridad jurídica, en la medida en que permitiría una mejor categorización de los contratos: a) los cubiertos por las directivas clásicas; b) los cubiertos por la directiva sobre contratos en el sector de la defensa; y c) los excluidos de todo marco comunitario.

2) Una información más amplia a escala comunitaria sobre los contratos en cuestión, y por lo tanto una mayor apertura de los contratos que permitiría a las industrias de defensa europeas participar en igualdad de condiciones en los concursos en todos los Estados miembros.

3) La introducción de la flexibilidad necesaria para la adjudicación de estos contratos, mediante la creación de un cuerpo de normas adaptadas a sus especificidades.

${ }^{44}$ arrowsmith, S. y Fernández Martín, J.M., "Developments in Public Procurement in 1992", European Law Review, 1993, p. 344.

${ }^{45}$ Miranda González, J., "La contratación de las Fuerzas Armadas...”, op. cit., p. 94 y WAINWRIGHT, R., "Legal Reforms in Public Procurement", Yearbook of European Law, 1990, p. 138. 
Los poderes adjudicadores serían los Ministerios de Defensa y las agencias que actúan para ellos, así como los demás Ministerios que efectúen compras de material militar.

Por otra parte, la aplicación de la directiva no prejuzgaría las posibilidades de excepciones conferidas a los Estados miembros en el marco de los acuerdos de la OMC y el Acuerdo sobre Contratación Pública.

Y lo más importante, los procedimientos que se establezcan deberían garantizar el respeto de los principios de transparencia y de no discriminación, teniendo en cuenta las peculiaridades de estos contratos. La norma debería exigir la publicación previa de un anuncio de los contratos. Unos criterios de selección acordados deberían permitir garantizar la no discriminación y la igualdad de trato entre las empresas, y tener en cuenta las particularidades de los contratos de defensa, como la confidencialidad, la seguridad de los aprovisionamientos y la protección del secreto de defensa.

\section{LOS CONTRATOS DE SERVICIOS Y SUMINISTRO PARA LA EJECUCIÓN DE PROYECTOS DE INVESTIGACIÓN}

La letra q) del artículo 4.1 deja fuera de la LCSP los contratos de servicios y suministro celebrados por los Organismos Públicos de Investigación estatales ${ }^{46}$ y los Organismos similares de las Comunidades Autónomas que tengan por objeto prestaciones o productos necesarios para la ejecución de proyectos de investigación, desarrollo e innovación tecnológica o servicios técnicos, cuando la presentación y obtención de resultados derivados de los mismos esté ligada a retornos científicos, tecnológicos o industriales susceptibles de incorporarse al tráfico jurídico y su realización haya sido encomendada a equipos de investigación del Organismo mediante procesos de concurrencia competitiva.

${ }^{46}$ De conformidad con lo previsto en el artículo 13 de la Ley 13/1986, de 14 de abril, de Fomento y Coordinación General de la Investigación Científica y Técnica, tienen la consideración de organismos públicos de investigación el Consejo Superior de Investigaciones Científicas (CSIC), el Centro de Investigaciones Energéticas, Medioambientales y Tecnológicas (CIEMAT), el Instituto Geológico y Minero de España (IGME), el Instituto Nacional de Técnica Aerospacial "Esteban Terradas" (INTA), el Instituto Nacional de Investigación y Tecnología Agraria y Alimentaria (INIA), el Instituto Español de Oceanografía (IEO) y el Instituto de Salud "Carlos III". No obstante, dentro del ámbito de la Administración General del Estado, existen otros organismos o entidades que desarrollan actividades de investigación y experimentación y que pueden englobarse, junto con los organismos públicos de investigación antes enumerados, en el concepto "Entes Públicos de Investigación", expresión empleada en el artículo 20 de la Ley de Patentes. 
En este sentido, el artículo 83 de la Ley Orgánica 6/2001, de 21 de diciembre, de Universidades, señala que los grupos de investigación reconocidos por la Universidad, los Departamentos y los Institutos Universitarios de Investigación, y su profesorado a través de los mismos o de los órganos, centros, fundaciones o estructuras organizativas similares de la Universidad dedicados a la canalización de las iniciativas investigadoras del profesorado y a la transferencia de los resultados de la investigación, podrán celebrar contratos con personas, Universidades o entidades públicas y privadas para la realización de trabajos de carácter científico, técnico o artístico, así como para el desarrollo de enseñanzas de especialización o actividades específicas de formación.

Los Estatutos de las Universidades, en el marco de las normas básicas que dicte el Gobierno, establecerán los procedimientos de autorización de los trabajos y de celebración de los contratos de investigación, así como los criterios para fijar el destino de los bienes y recursos que con ellos se obtengan ${ }^{47}$.

La sentencia del Tribunal Supremo, Sala Tercera, Sección 3. ${ }^{a}$, de 27 de octubre de 2005 (LA LEY 10177/2006) se pronuncia sobre el artículo 11 de la Ley de Reforma Universitaria, antecedente del artículo 83 de la Ley Orgánica de Universidades, rechazando la interpretación restrictiva del mismo que planteaban los recurrentes en el litigio en el sentido de que los contratos denunciados no se referirían a actividades de docencia, investigación o promoción de la cultura, exclusivo ámbito de actuación de la Universidad y de los sujetos enumerados en dicho precepto, sino de carácter profesional y técnico, por lo que dichas actividades no estarían amparadas por la ley. Se pretendía demostrar en el recurso ante el Supremo que los Departamentos, Institutos universitarios y profesores sólo y exclusivamente pueden contratar la realización de trabajos con esas finalidades "académicas": los contratos que excedan dichos fines serían contrarios a la ley, puesto que no estarían comprendidos en el precepto discutido, que es el que habilita a dichos sujetos a contratar trabajos externos a la Universidad siempre que estén encaminados a las finalidades de la institución universitaria.

Sin embargo, para el Tribunal Supremo:

“(...) esta interpretación restrictiva del artículo en cuestión, que implica la conclusión de que los contratos que no se refieran estrictamente a finalidades de

47 Por ejemplo, así lo hace el artículo 110 de los Estatutos de la Universidad de Castilla-La Mancha. En la misma la competencia del Rector para autorizar y celebrar contratos y convenios para la realización de trabajos de carácter científico, técnico o artístico, así como el desarrollo de cursos de especialización o actividades específicas de formación, así como la concesión de compatibilidad, en su caso, al personal docente de la UCLM que participe en dichas actividades, está delegada en el Vicerrector de Investigación (Resolución de 07 de mayo de 2004, DOCM de 27.05.04). 
docencia, investigación o fomento de la cultura se efectúan con infracción de la Ley de Reforma Universitaria, ha de ser rechazada. Tiene en efecto razón la Sala de instancia cuando así lo hace en el fundamento de derecho cuarto, reproducido supra, afirmando que no es posible deducir ni del propio precepto ni de una interpretación sistemática de la Ley las limitaciones a la facultad de contratación que propugnan las entidades actoras.

Además de las razones expuestas por la Sala de instancia, conviene añadir alguna consideración suplementaria. En primer lugar que, frente a lo que sostiene la parte actora, incluso si se asumiera que el marco de contratación externa de las Universidades y sus sujetos integrantes hubiera de mantenerse dentro del marco de las finalidades y objetivos de la institución académica, tampoco cabría la interpretación restrictiva propugnada. No hay más que revisar los preceptos de la propia Ley de Reforma Universitaria que las actoras aducen en apoyo de su posición para comprobar que dentro de dichas funciones cabe perfectamente la actividad cuya legalidad se discute. Así, no hay que olvidar que uno de los aspectos comprendidos en las funciones que el artículo 1.2 de la Ley de Reforma Universitaria atribuye a la Universidad se encuentra el de la transmisión de la ciencia, la técnica y la cultura a la sociedad, lo que no sólo se cumple a través de la docencia, sino asimismo mediante la transferencia de los resultados de la investigación y del saber universitario a la actividad económica, social y técnica. Dicha transferencia de saberes queda posibilitada muy principalmente gracias a la imbricación de la investigación efectuada por Departamentos, Institutos, Grupos de investigación y profesores en la actividad social y económica por medio de los contratos a los que se refiere el artículo 11 de la Ley.Así, el artículo 1.2.a) de la Ley de Reforma Universitaria se refiere a la transmisión y desarrollo de la ciencia, la técnica y la cultura y, sobre todo, el apartado c) del mismo precepto menciona expresamente el apoyo científico y técnico al desarrollo cultural, social y económico, tanto nacional como de las Comunidades Autónomas. Y esto no es contradicho, sino al contrario, por los preceptos que se refieren a los Departamentos, Institutos y Profesores universitarios.

Dicha transferencia de los resultados de la actividad de investigación y estudio universitarios a la sociedad es considerada hoy día universalmente como un rasgo esencial de la actividad universitaria, de tal forma que frente a lo que se afirma en el recurso, en todos los países de nuestro entorno se persigue activamente la imbricación de la Universidad en el tejido económico de la sociedad, sin perjuicio de que dicha interrelación deba producirse, como es obvio, dentro de un escrupuloso respeto a todas las exigencias del ordenamiento jurídico y, en particular, del derecho de la competencia.

$\mathrm{Y}$, en segundo lugar, y al contrario de lo que se indica por las entidades actoras, existe una manifiesta continuidad en este punto entre la Ley de Reforma Universitaria y la actualmente vigente Ley Orgánica de Universidades. En efecto, pese a los esfuerzos argumentativos del recurso, el texto del artículo 83 del texto regulador vigente de la Universidad española —-que se transcribe en el propio recurso-, no sólo reproduce en esencia el anterior artículo 11 de la Ley de Reforma Universitaria, sino que es más explícito en el sentido indicado. Así, se mencio- 
na como un nuevo sujeto de esta actividad contractual y de acuerdo con la experiencia comparada en investigación a los grupos de investigación, así como también una serie de organismos 'dedicados a la canalización de las iniciativas investigadoras del profesorado y a la transferencia de los resultados de la investigación' (sic), como lo son cualesquiera 'órganos, centros, fundaciones o estructuras organizativas similares de la Universidad'. Tampoco es un cambio que vaya en el sentido restrictivo propugnado por la parte actora el ańadir, como objeto de los contratos contemplados en el precepto, 'el desarrollo de enseńanzas de especialización o actividades específicas de formación', o la previsión de una habilitación a la potestad reglamentaria del Gobierno para que establezca el marco básico para la regulación por los Estatutos de las Universidades del procedimiento de autorización y celebración de tales contratos (que reitera lo que se indicaba ya en el artículo 45.1 de la Ley de Reforma Universitaria): se trata en ambos casos de prescripciones irrelevantes desde la perspectiva de la restricción del ámbito material sobre el que puedan versar dichos contratos que propugna la parte actora.

En definitiva, rechazada la interpretación que del artículo 11 de la Ley de Reforma Universitaria defienden las entidades recurrentes, y siendo correcta la efectuada por la Sala de instancia en el punto en el que la parte actora formula su discrepancia, es preciso rechazar el motivo".

El Supremo decidió por tanto no casar la Sentencia y asumir la interpretación del artículo 11 de la Ley de Reforma Universitaria en el sentido de que sí cubre la actividad contractual denunciada en el asunto, que resulta en ese sentido conforme a derecho. 
